\title{
Spatial Variability of the Background Diurnal Cycle of Deep Convection around the GoAmazon2014/5 Field Campaign Sites $\mathscr{0}$
}

\author{
Casey D. Burleyson, Zhe Feng, Samson M. Hagos, and Jerome Fast \\ Pacific Northwest National Laboratory, Richland, Washington \\ LUIZ A. T. MACHADO \\ National Institute for Space Research, São Paulo, Brazil \\ SCOT T. MARTIN \\ Harvard University, Cambridge, Massachusetts
}

(Manuscript received 18 August 2015, in final form 6 April 2016)

\begin{abstract}
The isolation of the Amazon rain forest makes it challenging to observe precipitation forming there, but it also creates a natural laboratory to study anthropogenic impacts on clouds and precipitation in an otherwise pristine environment. Observations were collected upwind and downwind of Manaus, Brazil, during the "Observations and Modeling of the Green Ocean Amazon 2014-2015" experiment (GoAmazon2014/5). Besides aircraft, most of the observations were point measurements made in a spatially heterogeneous environment, making it hard to distinguish anthropogenic signals from naturally occurring spatial variability. In this study, 15 years of satellite data are used to examine the spatial and temporal variability of deep convection around the GoAmazon2014/5 sites using cold cloud tops (infrared brightness temperatures colder than $240 \mathrm{~K}$ ) as a proxy for deep convection. During the rainy season, convection associated with the inland propagation of the previous day's sea-breeze front is in phase with the diurnal cycle of deep convection near Manaus but is out of phase a few hundred kilometers to the east and west. Convergence between the river breezes and the easterly trade winds generates afternoon convection up to $10 \%$ more frequently (on average $\sim 4 \mathrm{~mm} \mathrm{day}^{-1}$ more intense rainfall) at the GoAmazon2014/5 sites east of the Negro River (T0e, T0t/k, and T1) relative to the T3 site, which was located west of the river. In general, the annual and diurnal cycles of precipitation during 2014 were similar to climatological values that are based on satellite data from 2000 to 2013.
\end{abstract}

\section{Introduction and motivation}

The Amazon rain forest, one of a small number of regions of expansive continental deep tropical convection, contributes significantly to Earth's water cycle (e.g., Zeng et al. 2012). Latent heat released from convection over the Amazon is one of the drivers of the

Supplemental information related to this paper is available at the Journals Online website: http://dx.doi.org/10.1175/ JAMC-D-15-0229.s1.

Corresponding author address: Dr. Casey D. Burleyson, Pacific Northwest National Laboratory, P.O. Box 999/MS K9-24, Richland, WA 99352.

E-mail: casey.burleyson@pnnl.gov general circulation (Trenberth and Stepaniak 2004). Because of its remoteness and the sparseness of observations available there, the processes that determine the frequency and intensity of deep convection over the Amazon are inadequately understood and poorly modeled (Joetzjer et al. 2013; Yin et al. 2013). A variety of measurements were made during the "Observations and Modeling of the Green Ocean Amazon 20142015" field campaign (GoAmazon2014/5; Martin et al. 2016). GoAmazon2014/5 was one component of the broader Cloud Processes of the Main Precipitation Systems in Brazil: A Contribution to Cloud-Resolving Modeling and to the Global Precipitation Measurement (CHUVA) project designed to study precipitation regimes across Brazil (Machado et al. 2014). One of the primary goals of GoAmazon2014/5 was to understand the 

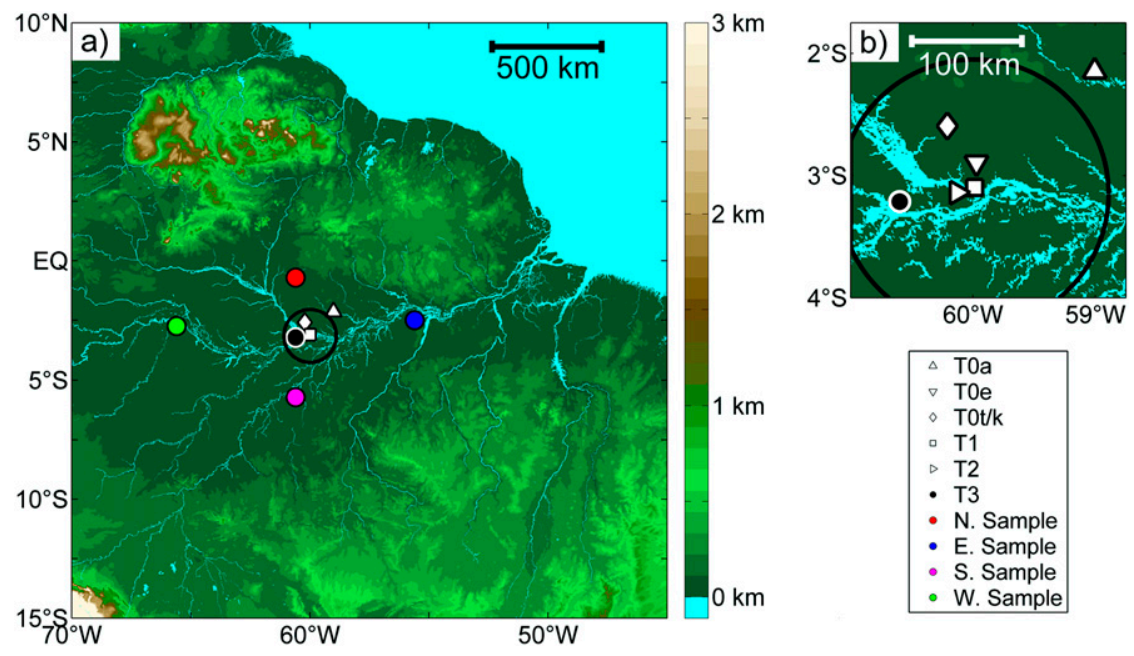

FIG. 1. (a) Height above sea level from a U.S. Geological Survey $30^{\prime \prime}$-resolution elevation dataset. The locations of the GoAmazon2014/5 sites are indicated by black and white symbols, and the locations of the four sample sites used for comparison are shown by the colored dots. The ARM AMF instrument suite was located at the T3 site. (b) Zoom of the area that includes the 110-km range ring (black circle) for the Manaus SIPAM radar.

influence of the large urban city of Manaus, Brazil, on aerosols, clouds, and precipitation in comparison with the background values. The city of Manaus, home to over 2 million people (IBGE 2015), is located in the middle of the Amazon basin where the Negro and Solimões (alternatively referred to as the Amazon in some Spanish-speaking countries) Rivers converge to form the Amazon River.

To quantify the influence of the city on aerosols, clouds, and precipitation, aircraft observations and multiple ground-based sites were utilized during GoAmazon2014/5 to measure the meteorological conditions upwind (typically clean) and downwind (at times polluted) of Manaus. Remote sensing measurements of clouds and precipitation along with ground-based meteorological and aerosol observations were made by the U.S. Department of Energy (DOE) Atmospheric Radiation Measurement (ARM) Mobile Facility (AMF; Mather and Voyles 2013). The AMF was located roughly $75 \mathrm{~km}$ downwind of Manaus at a site designated as T3 (Fig. 1). The other GoAmazon2014/5 surface sites (T0a, T0e, T0t/k, T1, and T2; Fig. 1) consisted of towerbased measurements within the boundary layer as well as ground-based measurements of the near-surface meteorological conditions and aerosols. In addition to analyzing the aircraft data collected during the two intensive operating periods (IOPs) of the campaign, comparison between the T1-T3 sites and the T0x sites (which were generally located to the north and east of the T1-T3 sites) has the potential to form the basis for determining the influence of Manaus on clouds, aerosols, and precipitation.
One possible complication could be the presence of naturally occurring spatial variability of deep convection around the GoAmazon2014/5 sites. In this case, any anthropogenic impacts will be superimposed on top of this background variability and differences in observed cloud properties between upwind and downwind sites may not be solely due to the effects of anthropogenic aerosols on clouds. Previous work has shown that the geography around Manaus can affect the spatial and temporal characteristics of clouds and precipitation (e.g., dos Santos et al. 2014 and references therein). The localized circulations driven by the rivers influence the spatial distributions of precipitation (Cutrim et al. 2000; Negri et al. 2002; Fitzjarrald et al. 2008; Paiva et al. 2011; dos Santos et al. 2014; Cohen et al. 2014; Tanaka et al. 2014). The complexity results not only from the circulations formed by differential heating over the rivers (i.e., dos Santos et al. 2014), but also the convergence generated when the zonal easterly trade winds divert meridionally along the Negro River, creating areas of convergence on the eastern banks and divergence on the western banks of the river as the diverted flows interact with the background winds (Silva Dias et al. 2004; Lu et al. 2005). In addition to the variability associated with the rivers, the convective squall line generated along the sea-breeze front, which often forms along the Brazilian coastline in the afternoon in response to heating over the land, can propagate far inland overnight and into the next day and could lead to spatial differences in the phase of the diurnal cycle of deep convection that may further complicate any 
analysis of the variability between the sites (e.g., Kousky 1980; Greco et al. 1990; Garstang et al. 1994; Cohen et al. 1995, 2014; Cutrim et al. 2000; Negri et al. 2000; Janowiak et al. 2005; Fitzjarrald et al. 2008).

The analysis that is presented here evaluates how the river breezes and the sea-breeze front affect the spatial and temporal variability of the frequency of deep convection around the GoAmazon2014/5 sites. This analysis of the background variability forms a reference point for future analyses of the anthropogenic impact of Manaus. Earlier studies describing the spatial variability of precipitation around Manaus mainly employed spatially sparse rain gauge and surface meteorological networks (e.g., Kousky 1980; Cutrim et al. 2000; Angelis et al. 2004; Fitzjarrald et al. 2008; dos Santos et al. 2014; Tanaka et al. 2014). More recent studies include satellite- or radar-based analyses of precipitation variability with limited temporal [e.g., Cohen et al. (2014) used 12-h radar composites to study the spatial variability and diurnal cycle of precipitation] or spatial [e.g., both Paiva et al. (2011) and dos Santos et al. (2014) used $0.25^{\circ} \times 0.25^{\circ}$ satellite data] resolutions. These studies may not have fully resolved the spatial variability and diurnal cycle of deep convection in the vicinity of the GoAmazon2014/5 sites.

In addition to facilitating an understanding of the anthropogenic influence of Manaus, the observations during GoAmazon2014/5 constitute one of the most extensive datasets ever collected over the Amazon and one of a few comprehensive datasets from a continental tropical environment. While not a primary focus of the GoAmazon2014/5 campaign, some researchers are using the datasets to evaluate and improve global climate models, many of which consistently struggle to reproduce the magnitude, timing, and spatial variability of precipitation across the Amazon basin (e.g., Joetzjer et al. 2013; Jones and Carvalho 2013; Yin et al. 2013; Gulizia and Camilloni 2015). While the detailed measurements of the campaign can contribute to addressing these issues, the Amazon is a vast rain forest and analysis is needed to consider how representative the GoAmazon2014/5 measurements are of the Amazon basin as a whole. As with all short-term field campaigns, the temporal representativeness of the measurement period also needs to be assessed. This is particularly true during the two IOPs, which were designed to collect a more complete set of measurements that would facilitate detailed analyses. The two IOPs during GoAmazon2014/5 were from 1 February to 31 March 2014 (IOP1) and from 15 August to 15 October 2014 (IOP2). These two IOPs represent the "wet" and "dry" seasons, respectively, although there is significant rainfall throughout the year (Rao et al. 1996; Zhou and Lau 1998; Gan et al. 2004; Raia and Cavalcanti 2008).

With these needs in mind, this paper focuses on an analysis of the spatial and temporal variability of the background frequency of clouds associated with deep convection around the GoAmazon2014/5 sites. Our analysis of the spatial complexity of the diurnal cycle builds on previous work describing the various multiscale forcing mechanisms for deep convection over the Amazon. We use the diurnal cycle to examine the similarities and differences across the research sites. This approach is appropriate because the forcing mechanisms that drive the spatial variability of deep convection have a strong diurnal component. There are three primary questions for our analysis:

1) How do the river-driven circulations around Manaus and the inland propagation of the sea-breeze front affect the diurnal cycle of deep convection around the GoAmazon2014/5 sites?

2) Are the characteristics of the diurnal cycle of deep convection at the GoAmazon2014/5 sites similar to those at other locations in the Amazon basin?

3) Was 2014, the principal year of the field campaign and the year of the two IOPs, a representative year for studying deep convection in the Amazon?

We examine the GoAmazon2014/5 site locations to characterize the naturally occurring spatial variability of deep convection in the study region. This baseline context of natural conditions can form the basis for future studies that focus on anthropogenic perturbations.

\section{Data and methods}

Our analysis is primarily built on a 15 -year geostationarysatellite climatological dataset (hereinafter "climatology") of the frequency of clouds associated with deep convection. For the Amazon, more than $70 \%$ of the total rainfall comes from convective precipitation (Biasutti and Yuter 2013, their Fig. 15). We use cold cloud tops as a proxy for the presence of clouds associated with deep convection. Satellite-based measurements provide a spatially complete dataset across the entire Amazon basin that facilitates comparison among multiple locations. We use geostationary-satellite data because the rapid update time ( $30 \mathrm{~min}$ in our case) allows for a more detailed analysis of the phase of the diurnal cycle relative to datasets collected on a processing low-orbital platform. We focus primarily on deepconvection frequency for two reasons: 1) the retrievals of precipitation intensity from geostationary satellites are 
relatively more uncertain, and thus we believe that frequency provides a more robust metric [see, e.g., Joyce et al. (2004) and Janowiak et al. (2005) and references therein], and 2) the climatology of precipitation accumulation is dominated by variations in precipitation frequency rather than intensity (Dai 2001; Schumacher and Houze 2006; Zipser et al. 2006; Biasutti et al. 2012; Biasutti and Yuter 2013).

The satellite data analyzed are the $11.5-\mu \mathrm{m}$ infrared (IR) brightness temperature ( $\mathrm{Tb}$ ) measurements packaged as the Global IR Dataset, a NASA Tropical Rainfall Measuring Mission (TRMM) ancillary dataset from the Climate Prediction Center of the National Centers for Environmental Prediction and the National Weather Service (Janowiak et al. 2001). The primary geostationary satellite making IR $\mathrm{Tb}$ measurements over the Amazon is the Geostationary Operational Environmental Satellites-East (GOES-East; Janowiak et al. 2001, their Fig. 1). The native temporal and spatial resolutions of the Global IR Dataset are $30 \mathrm{~min}$ and $4 \mathrm{~km} \times 4 \mathrm{~km}$, respectively. Because our concern is with the spatial and temporal variability of deep convection, we use the IR Tb data to look for the presence of clouds associated with deep convection in each 30-min scene. We use cloud tops with IR $\mathrm{Tb}<240 \mathrm{~K}$ as a proxy for deep convection. This threshold was also used by Hohenegger and Stevens (2013) to identify the onset of deep convection in a similar near-equatorial domain and is close to the 235-K threshold used by Laurent et al. (2002) and the 245-K threshold used by Machado et al. (1998) to identify deep convective cloud systems over the Amazon. Our threshold is $20 \mathrm{~K}$ warmer than the $220-\mathrm{K}$ threshold used to track mesoscale convective complexes over the Amazon by Ferreira et al. (2003). In contrast, Anagnostou et al. (1999) used a warmer temperature threshold of $253 \mathrm{~K}$ and a more complicated texture-based algorithm to separate convective and stratiform rainfall over the Amazon. A simple threshold of $240 \mathrm{~K}$ is adequate since we are primarily concerned with the presence or absence of clouds associated with deep convection rather than separating convective from stratiform rainfall or tracking individual convective cells in time. Although computed for the central United States, Feng et al. (2011, their Fig. 4) showed that roughly $75 \%$ of the total radar-estimated summertime rainfall comes from clouds with IR brightness temperatures colder than $240 \mathrm{~K}$.

We first create a binary mask of pixels colder than $240 \mathrm{~K}$ and then aggregate the masks in time to calculate the frequency of IR $\mathrm{Tb}<240 \mathrm{~K}$ on a variety of time scales. We refer to the frequency of IR Tb $<$ $240 \mathrm{~K}$ alternatively as the frequency of deep convection or the frequency of clouds associated with deep convection. Although the retrieved frequency of clouds associated with deep convection will shift higher or lower depending on the threshold used, the spatial patterns captured in the frequency maps are generally robust for a range of threshold values (Fig. 2). We minimize the impact of the choice of IR Tb threshold on our conclusions by interpreting the data in terms of the relative frequency rather than the absolute frequency of deep convective clouds.

We use data from 2000 to 2014, and our analysis is based on diurnal composites in 1-h local time (LT) intervals for December-February (DJF), MarchMay (MAM), June-August (JJA), and SeptemberNovember (SON). The annual cycle of precipitation in the Amazon basin is characterized by the driest season occurring during JJA, a transition from the dry season to the wet season during SON, the wettest season occurring during DJF, and a transition from the wet to the dry season during MAM (Rao et al. 1996; Zhou and Lau 1998; Gan et al. 2004; Raia and Cavalcanti 2008). We define the wet season as December-May. Up to $65 \%$ of the total annual rainfall in the central Amazon basin occurs during these six months (Rao et al. 1996, their Fig. 1). Separating the data seasonally allows us to capture seasonal variations in the amplitude and phase of the diurnal cycle. On average, each 1-h seasonal composite is made up of roughly 2300 scenes lasting $30 \mathrm{~min}$. The large sample size in each 1-h window ensures that whatever signals are present in our analysis are robust. Local time is computed at each individual $4 \mathrm{~km} \times 4 \mathrm{~km}$ pixel to minimize the spatial gradients in time across the domain. On occasion, this leads to small linear discontinuities because pixels from adjacent longitudes may be separated into different LT bins (see, e.g., the discontinuities at $60^{\circ} \mathrm{W}$ in Fig. 12, described in detail below). These discontinuities do not affect our analysis or conclusions.

To add weight to our conclusions drawn from the IR Tb deep-convection proxy, we evaluated the key patterns to be discussed later using the TRMM 3B42 precipitation dataset (Huffman et al. 2007). TRMM 3B42 provides a $0.25^{\circ} \times 0.25^{\circ}$ spatial resolution estimate of the 3-hourly mean rain rate generated using a combination of the TRMM instrument suite and geostationarysatellite precipitation retrievals from multispectral passive microwave and IR measurements. While the TRMM 3B42 dataset is not completely independent of the frequency composites for IR $\mathrm{Tb}<240 \mathrm{~K}$ (because TRMM 3B42 ingests IR Tb measurements from the geostationary satellites), the differences in our processing of the two datasets provide some degree of independent confirmation for our results. We use TRMM 


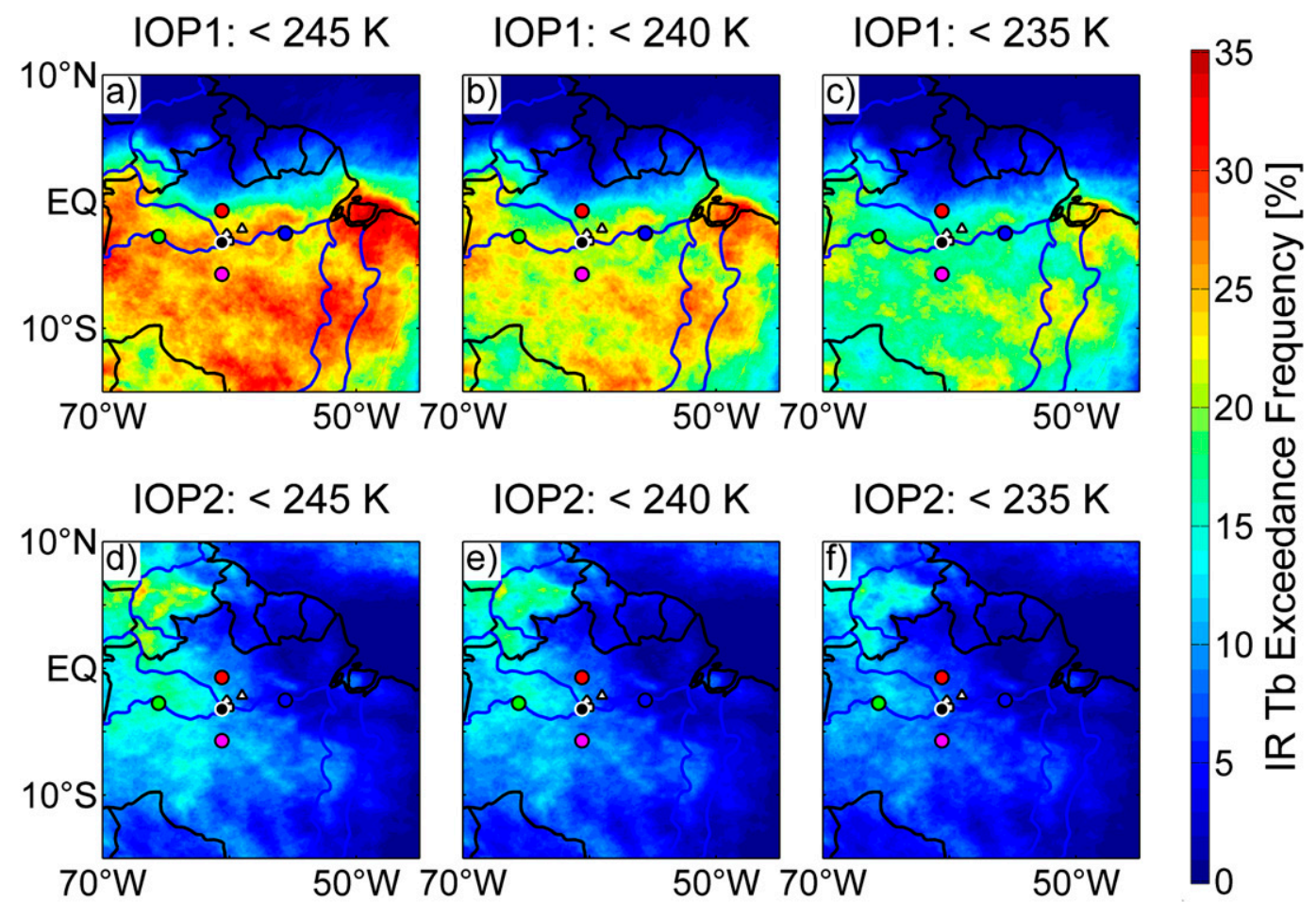

FIG. 2. Mean frequency of IR Tb colder than (left) 245, (center) 240, and (right) $235 \mathrm{~K}$ during (top) IOP1 (1 Feb31 Mar 2014) and (bottom) IOP2 (15 Aug-15 Oct 2014). The locations of the GoAmazon2014/5 sites use the same formatting as in Fig. 1a.

3B42 data from 2000 to 2014. All of the patterns found in our analysis of the Global IR Dataset are also present in the TRMM 3B42 dataset, albeit with minor differences primarily associated with discrepancies in the spatial and temporal resolution between the two datasets.

During GoAmazon2014/5, our Brazilian collaborators made available a limited amount of data from the Brazilian Amazonian Protection System (SIPAM) S-band (10-cm wavelength) radar near Manaus. At the time of this study we were able to obtain 17 months of data spanning from January 2014 through May 2015. The Manaus SIPAM radar has a $1.7^{\circ}$ beamwidth and completes a volume scan consisting of 17 sweeps (elevation angles ranging from $0.9^{\circ}$ to $19^{\circ}$ ) every $12 \mathrm{~min}$. The radial data were gridded onto a Cartesian grid with $2 \mathrm{~km} \times 2 \mathrm{~km} \times 0.5 \mathrm{~km}$ resolution (in the $x, y$, and $z$ dimensions). Calibration of the SIPAM radar data was performed on the basis of comparison with TRMM Precipitation Radar data and monitoring ground-clutter values (A. Funk and C. Schumacher 2016, personal communication). Our analysis of the SIPAM radar data is based on a rainfall retrieval that converts the measured radar reflectivities at a constant $2.5-\mathrm{km}$ height above the surface into an estimate of rain rate following a relation between reflectivity and rain rate $(Z-R)$ in which $Z=174.8 R^{1.56}$. As with all radar-derived rain products, there is considerable uncertainty in these retrievals, and thus we base our interpretation on the relative variability of the rain rate as opposed to the absolute values. We limit the use of SIPAM rain-rate estimates within $\sim 110 \mathrm{~km}$ radius from the radar. To reduce the noise in the SIPAM dataset, we computed the seasonal mean rain rate in 3-h windows across the diurnal cycle as opposed to 1 -h windows with the IR $\mathrm{Tb}<240 \mathrm{~K}$ frequencies. The size of the Manaus SIPAM radar sampling area $\left(\sim 38000 \mathrm{~km}^{2}\right)$ relative to the vastness of the Amazon basin (estimated at over 6.8 million $\mathrm{km}^{2}$ ) provides a clear rationale for our satellite-based climatological analysis. Without a broad-view satellite-based reference point with which to compare, it is challenging to understand the representativeness of the temporally and spatially constrained SIPAM dataset.

One approach that we employ to illustrate the similarity between the GoAmazon2014/5 sites and other locations in the Amazon basin is to compare the diurnal cycle of IR $\mathrm{Tb}<240 \mathrm{~K}$ frequency at multiple locations across the Amazon basin in addition to the GoAmazon2014/5 sites. Four additional locations (colored dots in Fig. 1a) were chosen to provide context for the GoAmazon2014/5 sites. We refer to the four comparative locations as the northern, eastern, southern, and western samples. All four comparison locations are 
(a)

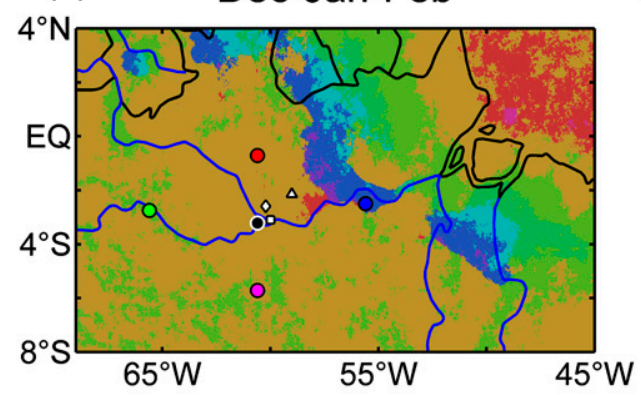

(c)

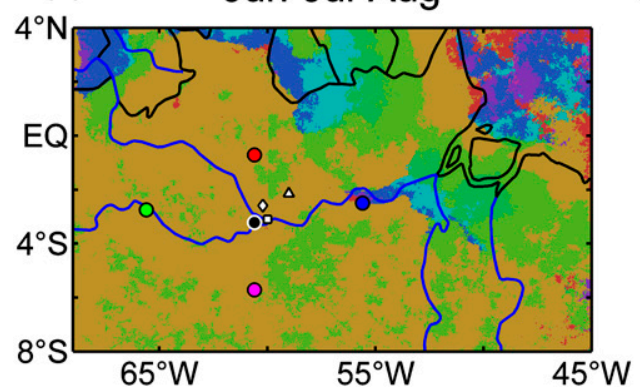

(b)

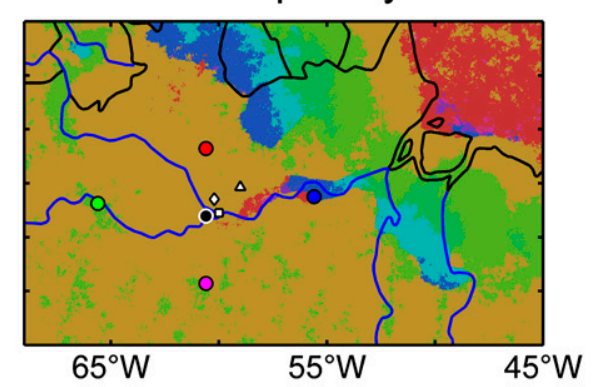

(d)

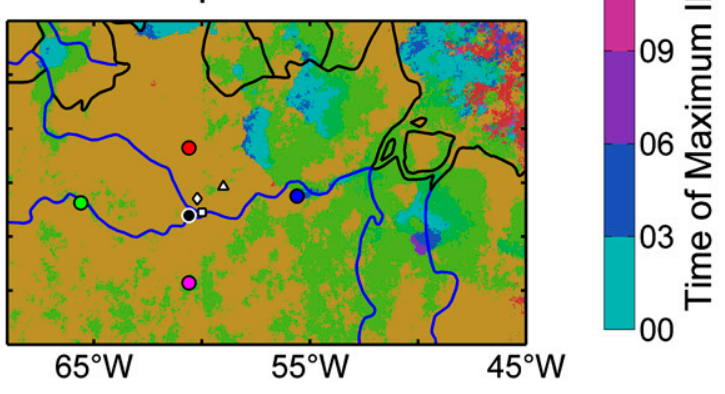

FIG. 3. Local time window of the maximum frequency of IR $\mathrm{Tb}<240 \mathrm{~K}$ during each season. The locations of the GoAmazon2014/5 sites use the same formatting as in Fig. 1a.

at an elevation that is similar to that of the T3 site, and the eastern and western samples are at a position along a river that is similar to that of the $\mathrm{T} 3$ site. The northern and southern samples are $\pm 2.5^{\circ}$ latitude $(\sim 275 \mathrm{~km})$ away from the T3 site, and the eastern and western samples are $\pm 5^{\circ}$ longitude $(\sim 555 \mathrm{~km})$ from the $\mathrm{T} 3$ site. Aside from these constraints, the positions of the four sites were essentially chosen arbitrarily, and our results are not sensitive to the exact location of the comparison samples. A comparison of the IR $\mathrm{Tb}<240 \mathrm{~K}$ diurnal cycle at these different locations can be imagined as a thought experiment. If the GoAmazon2014/5 sites or aircraft flights were at a different location within the Amazon basin, how might the diurnal cycle of deep convection observed at the sites possibly have been different? This question can best be answered using a satellite-based dataset that has homogenous sampling across the entire Amazon basin.

\section{Results}

\section{a. General characteristics of the diurnal cycle}

A robust diurnal cycle of deep convective frequency can be seen in all seasons, albeit with variations in the amplitude and timing of the diurnal maximum and minimum frequencies (Figs. 3-5). The spatial variability of the diurnal cycle can be most clearly seen in movies for each season, which are included in the online supplement to this article (Figs. S1-S4). Some common elements are observed across the inland Amazon basin. In general, the frequency of clouds associated with deep convection begins to increase from 0900 to $1200 \mathrm{LT}$ and maximizes across much of the Amazon basin between 1500 and 1800 LT (Fig. 3; see also supplemental Figs. S1-S4). Exceptions to this afternoon peak occur along the Amazon River east of the GoAmazon2014/5 sites and in areas of elevated terrain. The afternoon increase in the frequency of deep convection is driven by the radiatively forced diurnal cycles of surface heating, evapotranspiration, and low-level instability (Martin et al. 1988; Betts et al. 2002; dos Santos et al. 2014). Over and alongside the rivers, these favorable conditions are short circuited by temperature-driven divergent flows, which induce subsidence over water in the afternoon (Cutrim et al. 2000; Fitzjarrald et al. 2008; Paiva et al. 2011; Cohen et al. 2014; dos Santos et al. 2014). The impact of these circulations will be discussed in more detail in section $3 \mathrm{c}$. The time of minimum IR $\mathrm{Tb}<240 \mathrm{~K}$ frequency is more spatially variable compared than is the time of maximum frequency (Fig. 4). During the rainy season, the areas around the GoAmazon2014/5 sites have a minimum frequency in the early-morning hours. Across most of the rest of the domain the minimum IR $\mathrm{TB}<240 \mathrm{~K}$ frequency occurs between sunrise and 
(a)

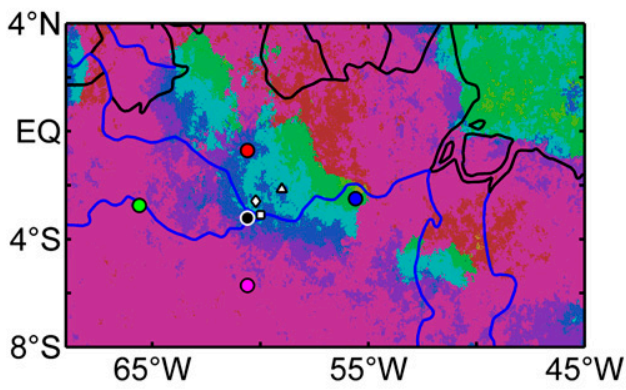

(c)

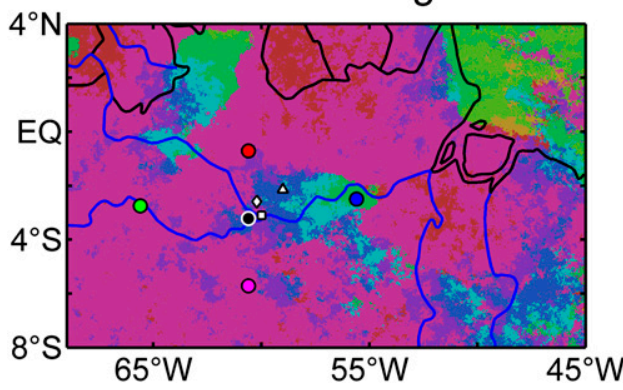

(b)

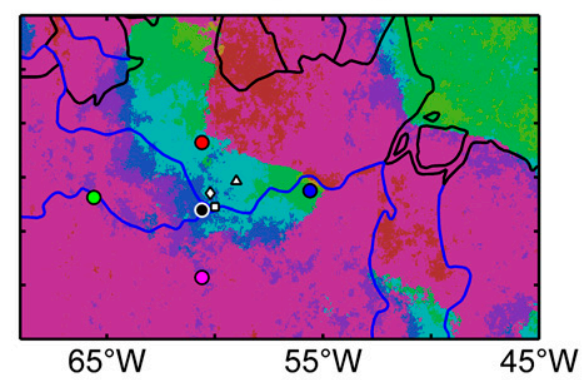

(d)

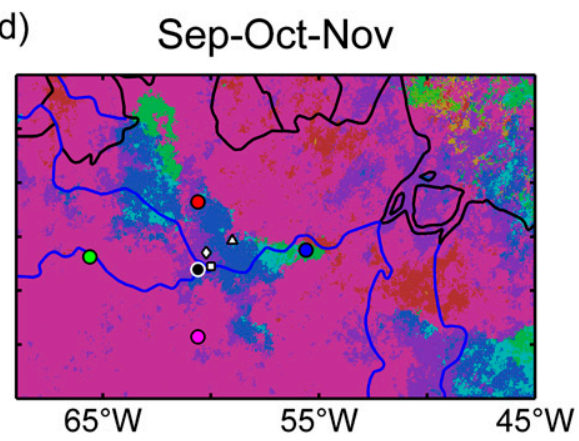

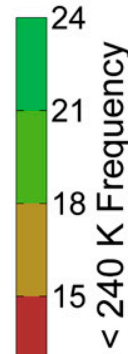

$12 \stackrel{\circ}{\circ}$

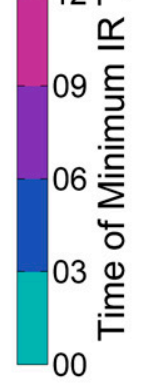

FIG. 4. As in Fig. 3, but for the minimum frequency.

noon. The amplitude of the IR $\mathrm{Tb}<240 \mathrm{~K}$ diurnal cycle varies widely among the seasons and by location across the Amazon basin (Fig. 5). Of interest is that regions with a smaller-amplitude diurnal cycle are the same areas over which the frequency of convection maximizes overnight (e.g., cf. Fig. 3 with Fig. 5). Much of the variability in the amplitude of the diurnal cycle is related to spatially varying forcing mechanisms responsible for (a)

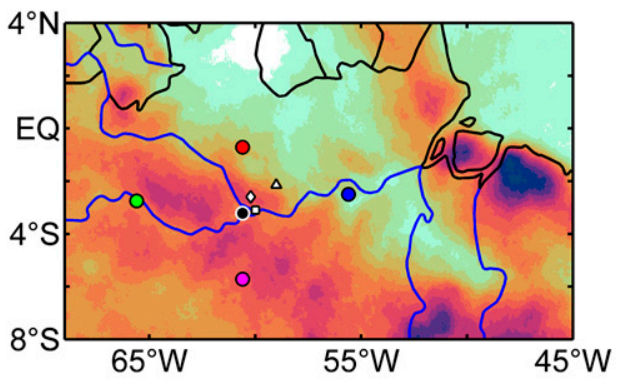

(c)

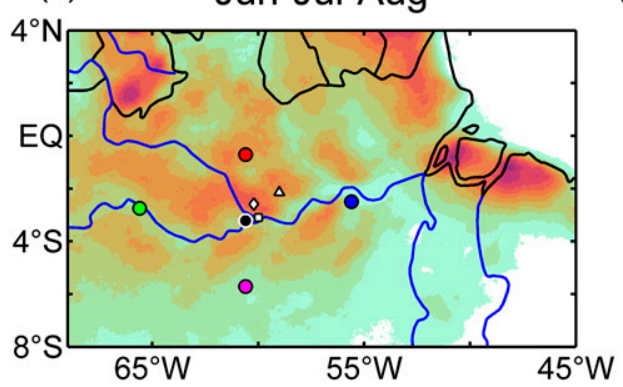

(b)

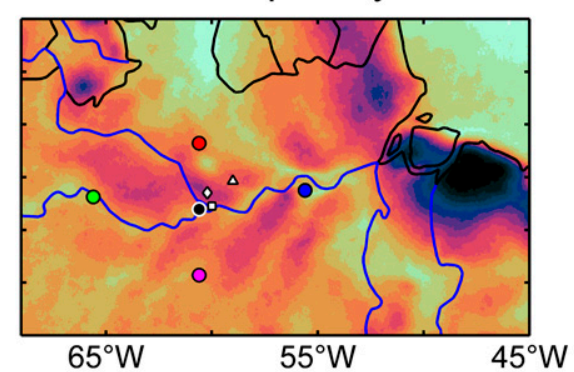

(d)

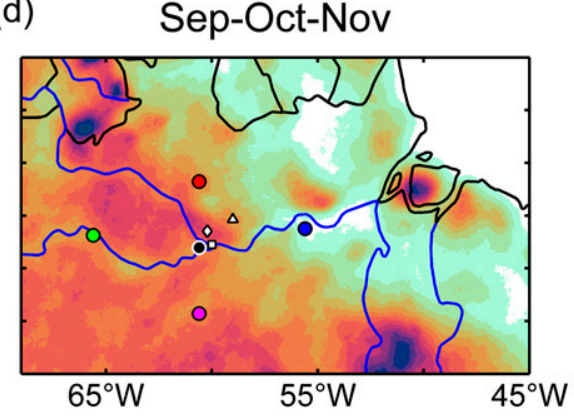

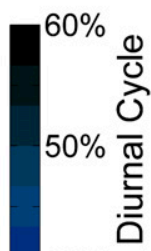

$40 \% \underline{\Upsilon}$

온

$30 \%$

o

$\underline{\underline{ }}$

$-20 \%$

焉

$-10 \%$

$0 \%$

FIG. 5. Amplitude of the frequency of the diurnal cycle of IR brightness temperatures colder than $240 \mathrm{~K}$ (IR Tb $<$ $240 \mathrm{~K}$ ) during each season. The amplitude is calculated as the difference between the maximum and the minimum frequency at any time of day. 

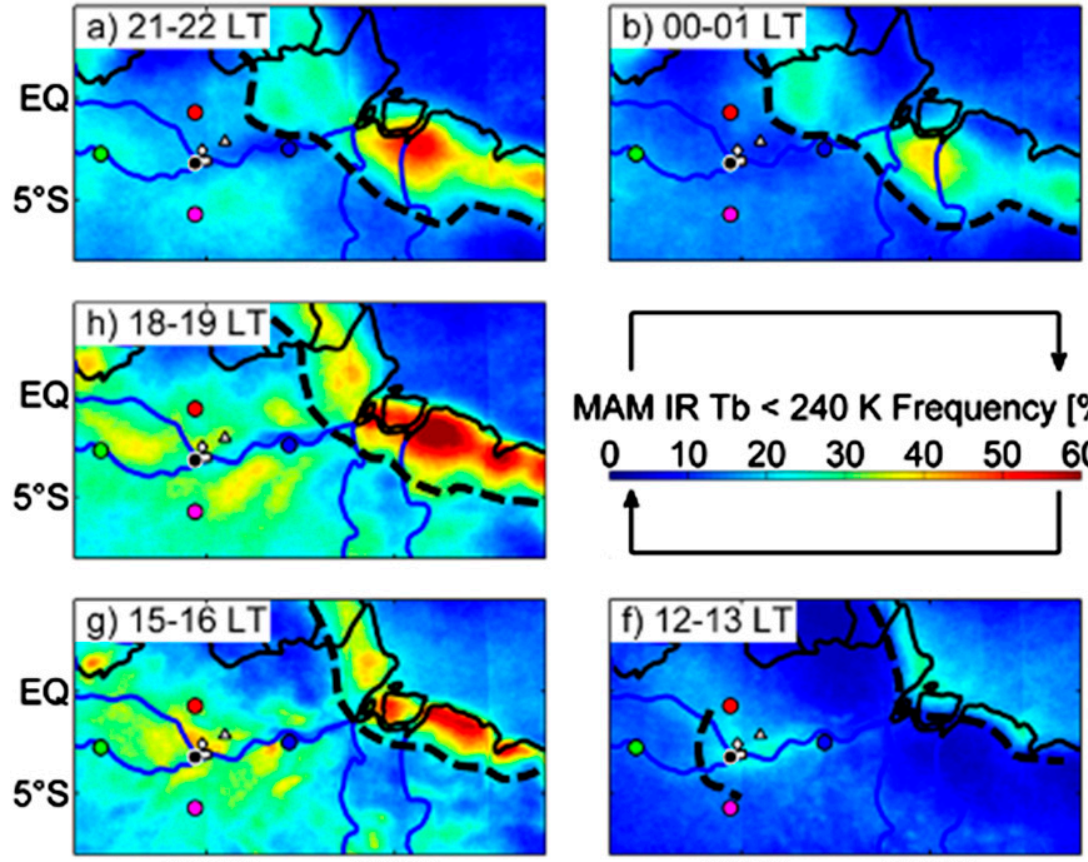

$60^{\circ} \mathrm{W}$

$50^{\circ} \mathrm{W}$

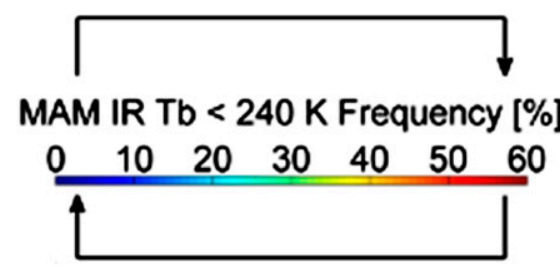

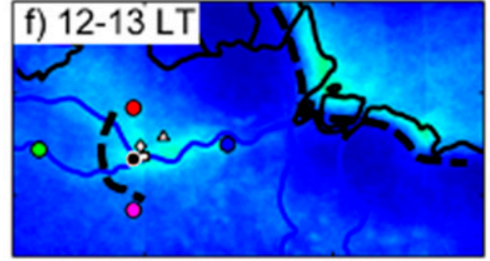

$60^{\circ} \mathrm{W}$

$50^{\circ} \mathrm{W}$
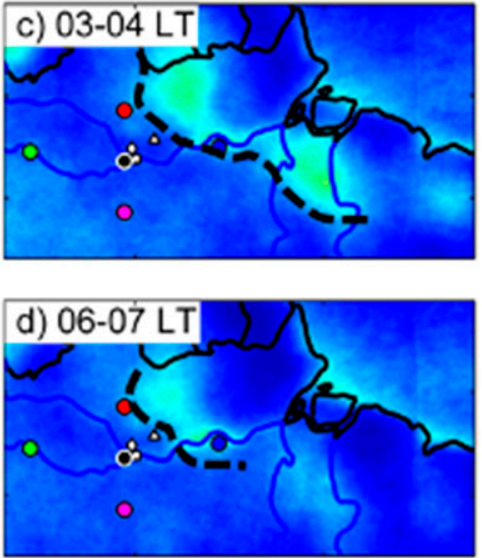

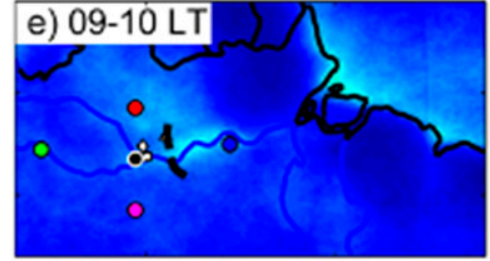

$60^{\circ} \mathrm{W}$

$50^{\circ} \mathrm{W}$

FIG. 6. Mean frequency of IR Tb $<240 \mathrm{~K}$ in 1-h windows across the diurnal cycle during MAM. The approximate leading edge of the sea-breeze front is indicated by the dashed black line; LT for each 1-h window is indicated at the top left of each box. The locations of the GoAmazon2014/5 sites use the same formatting as in Fig. 1a.

initiating convection. Two specific mechanisms, the inland propagation of the squall line formed by the sea-breeze front and river-driven circulations, will be discussed in detail in sections $3 b$ and $3 c$.

\section{$b$. Inland propagation of the sea-breeze front}

The movies from DJF and MAM illustrate the clear inland propagation of a line of deep convection originally associated with the sea-breeze front (Fig. 6; see also supplemental Figs. S1 and S2). The sea-breeze front frequently forms along the coastline in the afternoon as a result of stronger heating over land than over the adjacent water. Although the convection propagates as a squall line, we will refer to it as the seabreeze front since this is the initial forcing mechanism that leads to the linear structure of the convection. The inland propagation of the sea-breeze front [alternatively called the Amazon coastal squall line (ACSL)] appears to have been first noted by Kousky (1980) and has been discussed in numerous papers since then (e.g., Garstang et al. 1990, 1994; Cohen et al. 1995, 2014; Cutrim et al. 2000; Negri et al. 2000; Angelis et al. 2004; Janowiak et al. 2005; Fitzjarrald et al. 2008). Greco et al. (1990, their Table 1) showed that up to $40 \%$ of the total rain accumulation at four rain gauge sites north of Manaus could be attributed to mesoscale convective systems originating along the Brazilian coastline.
Although the inland propagation of the sea-breeze front does not occur every day, it occurs often enough for the signal to clearly appear in our 15-year composite climatology. With respect to the sea-breeze front, we set out to answer two questions: 1) How does the sea-breeze front impact the diurnal cycle of deep convection around the GoAmazon2014/5 sites? 2) How does the sea-breeze front impact the correlation between the diurnal cycle at the GoAmazon2014/5 sites and other locations in the Amazon basin? A majority of the previous analyses of the sea-breeze front have been based on satellite case studies of individual sea-breeze events or rain gauge data (e.g., Kousky 1980; Garstang et al. 1990; Greco et al. 1990; Cohen et al. 1995, Cutrim et al. 2000; Angelis et al. 2004; Fitzjarrald et al. 2008). Our 15-year composite satellite climatology allows us to identify specific spatial features that may be unresolved in rain gauge datasets and temporal variability that may be unresolved in studies that are based on sun-synchronous rather than geostationarysatellite data.

The impact of the sea-breeze front can be seen by comparing the IR $\mathrm{Tb}<240 \mathrm{~K}$ diurnal cycle at the $\mathrm{T} 3$ site and the four sample sites we use for comparison (Fig. 7). The variability is pronounced during the wet season. In both DJF and MAM the sea-breeze front, which can be seen as a coherent linear feature of 
(a) Dec-Jan-Feb

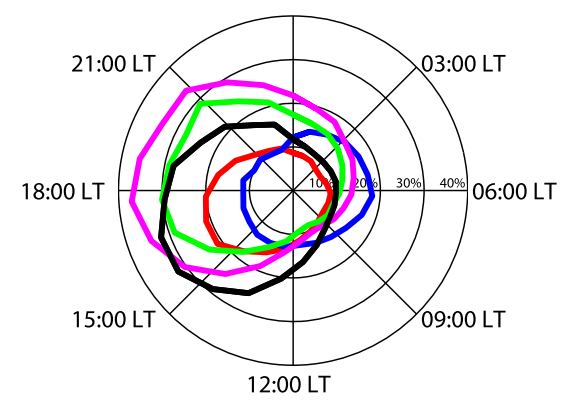

(c) Jun-Jul-Aug

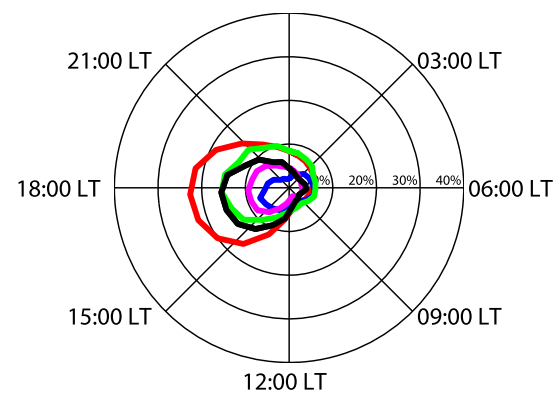

(b) Mar-Apr-May

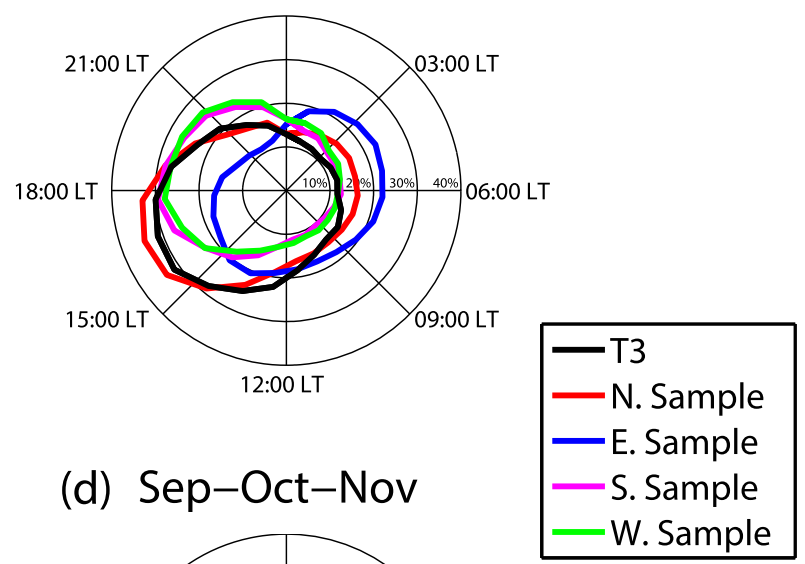

FIG. 7. Diurnal cycle of the mean frequency of IR $\mathrm{Tb}<240 \mathrm{~K}$ during each season at the $\mathrm{T} 3$ site (black) and the four sites used for comparison (Fig. 1a); LT proceeds clockwise around each circle, and the frequency of IR Tb $<240 \mathrm{~K}$ is indicated by the distance from the center of the plot.

enhanced IR Tb $<240 \mathrm{~K}$ frequency, first appears onshore between 1200 and 1300 LT (Fig. 6f; see also supplemental Figs. S1 and S2). By 1800 LT the convection associated with the sea-breeze front has moved several hundred kilometers onshore and generally stretches from $5^{\circ} \mathrm{N}$ to $5^{\circ} \mathrm{S}$ (Fig. 6h). After $1800 \mathrm{LT}$ the front continues to move inland with a motion that is generally west-southwesterly during DJF and more westerly during MAM (Figs. 6a-f; see also supplemental Figs. S1 and S2). Convection associated with the sea-breeze front passes the location of our eastern sample between 0000 and 0600 LT (Figs. 6b,c and 7a,b). This creates a distinct nocturnal peak in IR $\mathrm{Tb}<$ $240 \mathrm{~K}$ frequency at our eastern sample (blue lines in Figs. 7a,b). This nocturnal peak in the frequency of deep convection upwind of Manaus was observed in rain gauge data collected near Santarém, Brazil (located at $\sim 55^{\circ} \mathrm{W}$, which is roughly the same longitude as our eastern sample), by Cohen et al. $(1995,2014)$ and Fitzjarrald et al. (2008). In contrast to the eastern sample, because it takes the sea-breeze front longer to reach Manaus and the GoAmazon2014/5 sites, the convection associated with this propagating signal is generally in phase with the solar-forced diurnal cycle of convection at the GoAmazon2014/5 sites. This leads to a single afternoon peak in IR $\mathrm{Tb}<240 \mathrm{~K}$ frequency at the T3 site (black lines in Figs. 7a,b). Our finding that the previous day's sea-breeze front arrives at the GoAmazon2014/5 sites in phase with the background diurnal cycle is consistent with previous studies (Harriss et al. 1990; Garstang et al. 1994; Cutrim et al. 2000; Angelis et al. 2004). The arrival of the sea-breeze front is not captured in the Manaus SIPAM dataset because of the relatively small sampling domain of the radar and the fact that the front arrives in phase with the background diurnal cycle. This provides a compelling justification for using a satellite climatology to resolve the large-scale forcing mechanisms that drive the variability of the diurnal cycle of convection observed at the GoAmazon2014/5 sites. Downwind of the T3 site the propagating convection arrives after the peak of the background diurnal cycle and acts to extend daytime convection into the late-night and early-morning hours (green lines in Figs. 7a,b). This may be due to a combination of the continuing propagation of the sea-breeze front as well as new convection forming in the confluence region around Manaus and propagating downwind. Rickenbach (2004) described several case studies in which the sea-breeze front propagated all the way across the Amazon basin into southwestern 


\section{(a)}
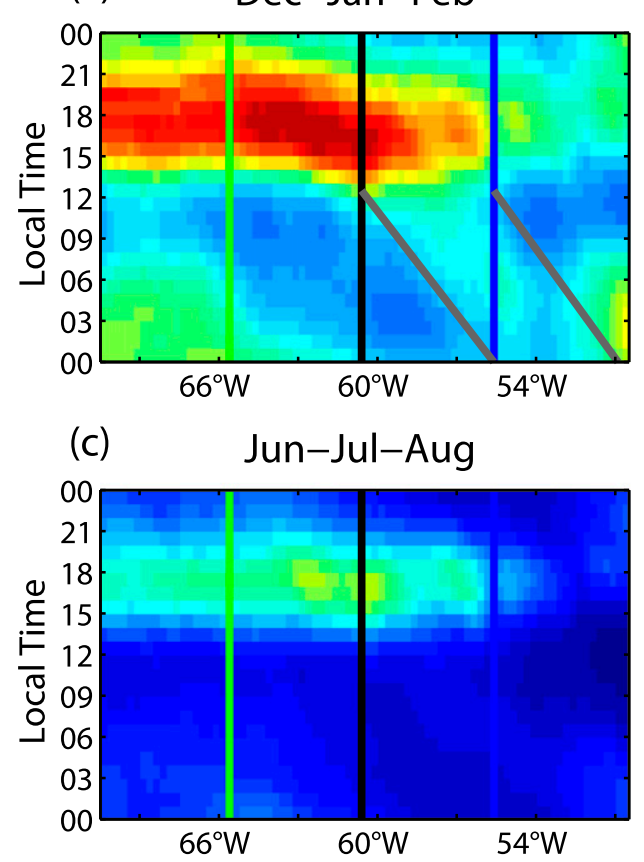

(b) Mar-Apr-May

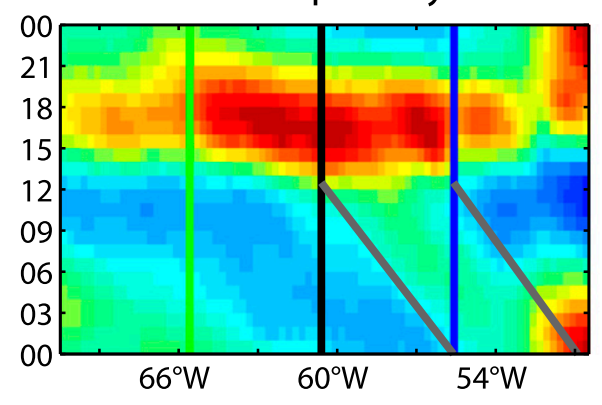

(d) Sep-Oct-Nov

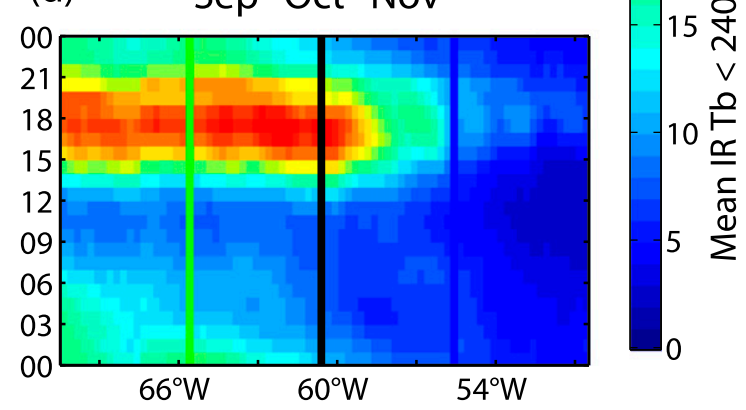

FIG. 8. Hovmöller diagrams showing the diurnal cycle ( $y$ axes) of the frequency of IR $\mathrm{Tb}<240 \mathrm{~K}$ as a function of longitude ( $x$ axes) during each season. The approximate bounds of the sea-breeze front during DJF and MAM are shown by the diagonal gray lines. The locations of the T3 site and the eastern and western sites used for comparison with T3 are indicated by the black, blue, and green lines, respectively. Frequencies are averaged in $0.25^{\circ}$ longitude bins from $4.2^{\circ}$ to $2.2^{\circ} \mathrm{S}$ (roughly $\pm 1^{\circ}$ latitude from the $\mathrm{T} 3$ site).

Amazonia $36 \mathrm{~h}$ after it initially formed along the Brazilian coastline.

A comparison of the $\mathrm{T} 3$ site with other locations along the Amazon River illustrates that the wet-season diurnal cycle of deep convection in the Amazon involves a superposition of the radiatively forced diurnal cycle and the lateral translation of the sea-breeze front. In different places along the Amazon River these two forcing mechanisms are either in or out of phase with each other. These patterns are apparent in Hovmöller diagrams of the diurnal cycle of IR $\mathrm{Tb}<240 \mathrm{~K}$ frequency (Fig. 8). The inland propagation of the sea-breeze front during DJF and MAM can be seen as the westward-moving band of enhanced IR $\mathrm{Tb}<240 \mathrm{~K}$ frequency that originates east of $54^{\circ} \mathrm{W}$ in the afternoon and arrives at the T3 site the following afternoon (Figs. 8a,b). Using the Hovmöller diagrams, we can estimate the phase speed of the convection associated with the propagating sea-breeze front as being roughly $0.4-0.5^{\circ} \mathrm{h}^{-1}\left(\sim 45-55 \mathrm{~km} \mathrm{~h}^{-1}\right)$. This value is consistent between DJF and MAM and agrees with previous estimates of $\sim 50-60 \mathrm{~km} \mathrm{~h}^{-1}$ from case studies of the ACSL (Garstang et al. 1990, 1994; Cohen et al. 1995).

The inland propagation of the sea-breeze front and its phasing with respect to the background diurnal cycle are an important factor for interpreting the diurnal cycles observed at the GoAmazon2014/5 sites. When it does occur, on average the sea-breeze front would arrive at the T0e, T0t/k, T1, T2, and T3 sites within an hour of each other, but the T0a site would observe the deep convection from the sea-breeze front earlier in the day than would the T3 site. Furthermore, the movies showing the propagation of the sea-breeze front indicate that it gradually becomes confined to the area immediately around the Amazon River in the midmorning hours (Figs. 6d-f; see also supplemental Figs. S1 and S2). One theory behind this narrowing of the front is that the convection is channeled by gradients in elevation along the river valley (Fitzjarrald et al. 2008; Cohen et al. 2014). The narrowing of the front means that, while the composite IR $\mathrm{Tb}<240 \mathrm{~K}$ frequency maps show the seabreeze front impacting all of the GoAmazon2014/5 sites, on any given day that the sea-breeze front propagates inland the T0a site, which is typically expected to represent cleaner aerosol conditions, might naturally experience earlier or less convection from the residual front than might the other GoAmazon2014/5 sites. For example, the small secondary peak in convection from 0600 to 0900 LT at the T0a site in DJF (Fig. 10a, described below) may be due to the passage of the seabreeze front.

The timing and spatial extent of the sea-breeze front could lead to differences in the frequency of deep 
convection between the $\mathrm{T} 3$ and $\mathrm{T} 0 \mathrm{a}$ sites that arise purely from differences in location with respect to the Amazon River and Brazilian coastline. The distinct in- and out-of-phase elements resulting from the interactions between the sea-breeze front and the background diurnal cycle also mean that the wet-season diurnal cycle observed at the GoAmazon2014/5 sites has a different phase than does the diurnal cycle at other longitudes a few hundred kilometers away along the Amazon River (e.g., the two east-to-west hypothetical sites used in our comparative analysis). In other words, had the GoAmazon2014/5 sites been located at a different longitude along the Amazon River the phase of the diurnal cycle of deep convection they observed would be expected to have been significantly different.

\section{c. Spatial variability driven by river circulations}

We showed in the previous section that the position of the GoAmazon2014/5 sites with respect to the distance from the coast can impact the timing of the diurnal cycle of deep convection that occurs over the sites. In a similar way, the location of the sites in the confluence region near Manaus can also impact the frequency and timing of deep convection occurring around the sites. Previous work has demonstrated that the Amazon River has a suppressing effect on daytime convection because of the divergence and subsequent subsidence from the thermally direct circulations associated with differential heating over the river (Garstang et al. 1990; de Oliveira and Fitzjarrald 1993; Cutrim et al. 2000; Angelis et al. 2004; Fitzjarrald et al. 2008; Adams et al. 2011; Paiva et al. 2011; Cohen et al. 2014; dos Santos et al. 2014). The daytime suppression of convection over the Amazon River is an easily identifiable feature in the map-view plots of afternoon IR $\mathrm{Tb}<240 \mathrm{~K}$ frequency (Figs. $6 \mathrm{~g}, 6 \mathrm{~h}$, and $9 \mathrm{~b}$; see also supplemental Figs. S1 and S2). Much of the previous work investigating river influences on convection has relied on rain gauge networks (Garstang et al. 1990; Cutrim et al. 2000; Angelis et al. 2004; Fitzjarrald et al. 2008; Adams et al. 2011) and on satellite data at a $0.25^{\circ}$ or coarser resolution (Paiva et al. 2011; dos Santos et al. 2014). Cohen et al. (2014) used three years of composite radar-derived rainfall maps to study the impacts of the river circulations in the AmazonTapajós confluence region. Because their radar domain was several hundred kilometers to the east of the GoAmazon2014/5 sites and the spatial configuration of the rivers in the Amazon-Tapajós confluence region is different than in the Negro-Solimões-Amazon confluence region, it is not clear how relevant their results are for understanding river impacts on the GoAmazon2014/5 sites. With respect to the GoAmazon2014/5 measurements, we ask whether the position of the sites with respect to the rivers affects the frequency or timing of convection that they observed.

The suppression of deep convection over the Amazon River becomes apparent after $1200 \mathrm{LT}$ and extends until $2100 \mathrm{LT}$, at which point the afternoon convection diminishes everywhere and a comparable frequency is observed over the river and the surrounding areas to the north and south (Fig. 6; see also supplemental Figs. S1 and S2). During the peak of the afternoon convection, the width of the suppression area extends roughly $50 \mathrm{~km}$ away from the Amazon River (Fig. 9b). This distance is consistent with the $25-50-\mathrm{km}$ rain gauge-based estimates found in the literature for the Amazon River (Fitzjarrald et al. 2008; Cohen et al. 2014; dos Santos et al. 2014). There is a clear suppression of afternoon convection over the Amazon River, but the smaller north-south-oriented tributaries branching off the main Amazon channel have a different impact. In agreement with previous work, Fig. 9b shows that these smaller rivers typically have enhanced IR $\mathrm{Tb}<240 \mathrm{~K}$ frequency on their eastern shorelines and a slight suppression over the river and on the western shores (Silva Dias et al. 2004; Lu et al. 2005; dos Santos et al. 2014); dos Santos et al. (2014) attributed these patterns to alternating areas of convergence and divergence as the river-induced thermal circulations interact with the background easterly trade winds. The western-shoreline divergence signal is likely counteracted to some degree by a slight mechanical lifting from convergence as winds flowing over the low-friction rivers are slowed by friction as they return to the downwind shoreline ( $\mathrm{Lu}$ et al. 2005).

These east-west gradients in the frequency of deep convection have a large impact on the variability among the GoAmazon2014/5 sites. The sites straddle the Negro River, which is oriented from northwest to southeast in the confluence region (Fig. 1b). Daytime convergence on the eastern shore of the Negro River and divergence on the western shore lead to up to $10 \%$ more frequent afternoon deep convection at the T0e, $\mathrm{T} 0 \mathrm{t} / \mathrm{k}$, and $\mathrm{T} 1$ sites than at the $\mathrm{T} 3 \mathrm{site}$ in every season except DJF (Figs. 9b, 9c and 10b-d). A similar pattern of enhanced rain rate east of the Negro River is observed in the Manaus SIPAM data for MAM during 2014-15 (Fig. 11). The mean afternoon rain rate east of the river is on average $4 \mathrm{~mm} \mathrm{day}^{-1}$ larger than the areas west of the river (Table 1). This result can also be inferred from the TRMM precipitation maps in dos Santos et al. (2014, their Fig. 7). With respect to the GoAmazon2014/5 sites, the enhancement of convection east of the Negro River contributes to a $21 \%$ 

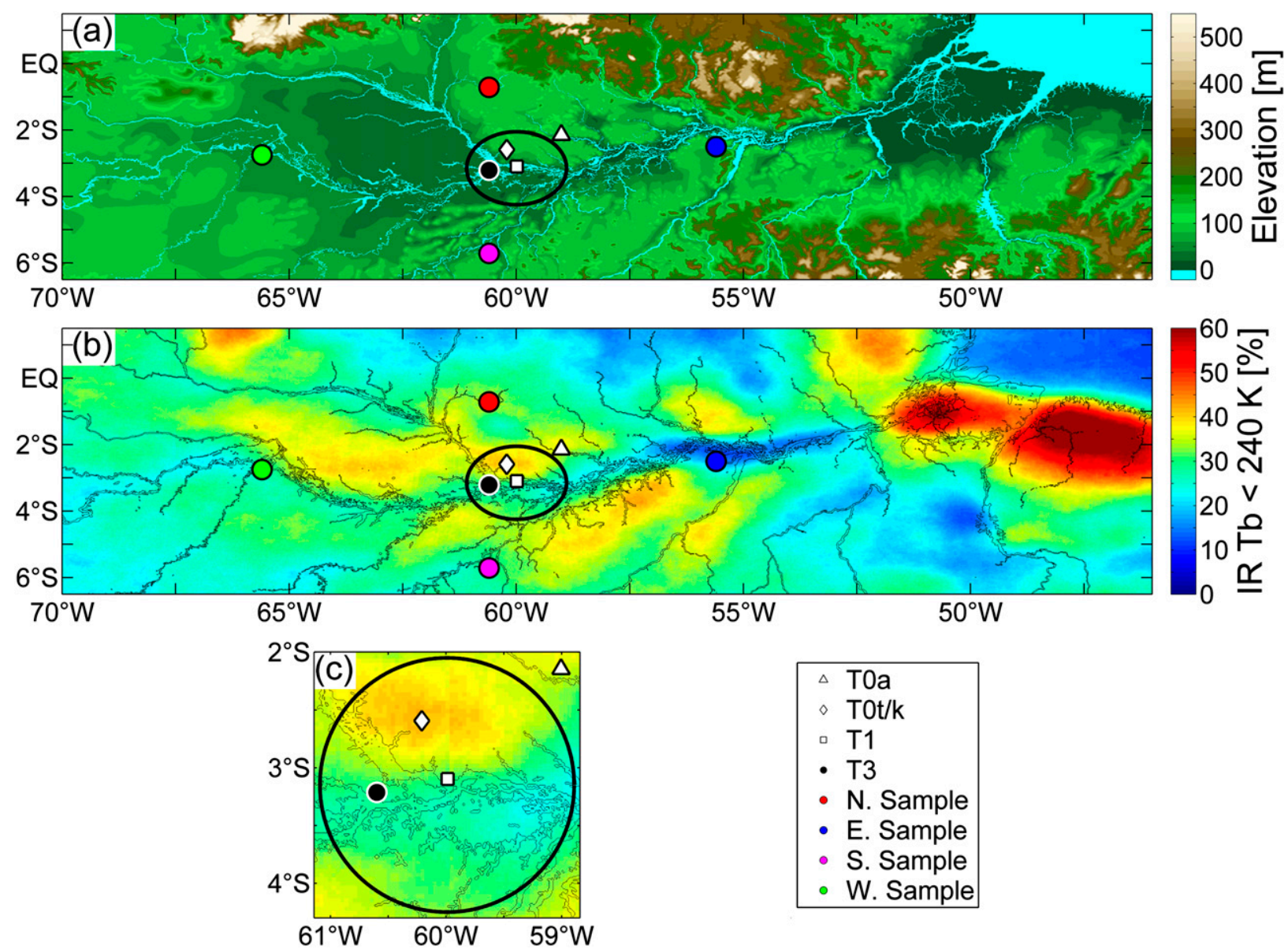

FIG. 9. (a) Zoomed-in elevation map using the same dataset as in Fig. 1. (b) The mean frequency of IR Tb $<240 \mathrm{~K}$ from 1700 to $1800 \mathrm{LT}$ during MAM. (c) A zoomed-in version of (b) using the same domain as in Fig. 11, below. The locations of the GoAmazon2014/5 sites use the same formatting as in Fig. 1a, and outlines of the rivers are shown by the black lines. The 110-km-range ring for the Brazilian SIPAM radar is indicated by the black circle.

relative enhancement in afternoon $\mathrm{IR} \mathrm{Tb}<240 \mathrm{~K}$ frequency at the $\mathrm{T} 0 \mathrm{t} / \mathrm{k}$ sites when compared with the $\mathrm{T} 3$ site and a $36 \%$ relative enhancement in the mean afternoon rain rates observed by the Manaus SIPAM radar (Table 1). While clearly impacting the mean rain rate and the maximum frequency of clouds associated with deep convection, these localized river effects do not appear to drastically change the phase of the diurnal cycle at the GoAmazon2014/5 sites (Figs. 3, 4, and 10). The enhancement of deep-convection frequency at the GoAmazon2014/5 sites east of the Negro River adds further evidence that the background spatial variability needs to be accounted for when comparing measurements made at the $\mathrm{T} 3$ site with the measurements made at the T0e, T0t/k, and $\mathrm{T} 1$ sites. For example, differences in cloud properties and precipitation among these sites may be more due to natural dynamic and thermodynamic effects than to the anthropogenic aerosol effects associated with Manaus emissions. The fact that there are coherent east-west spatial patterns of convection frequency across all of the north-south-oriented tributaries in the Amazon basin (Fig. 9) adds further support that the afternoon differences between the GoAmazon2014/5 sites are not a phenomenon specific to the Manaus confluence region.

\section{d. Similarity between the GoAmazon2014/5 sites and other locations in the basin}

One of the goals of our analysis has been to assess the similarities between the diurnal cycle of deepconvection frequency at the GoAmazon2014/5 sites and other locations across the Amazon basin. One final way to approach this is to calculate the correlations between the diurnal cycle of IR $\mathrm{Tb}<240 \mathrm{~K}$ frequency at the T3 site, where the most extensive measurements of clouds and precipitation were made, and all other locations within the Amazon basin. Seasonal maps of 
(a) Dec-Jan-Feb

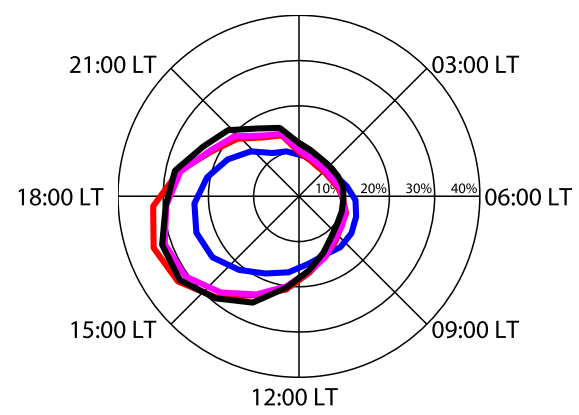

(c) Jun-Jul-Aug

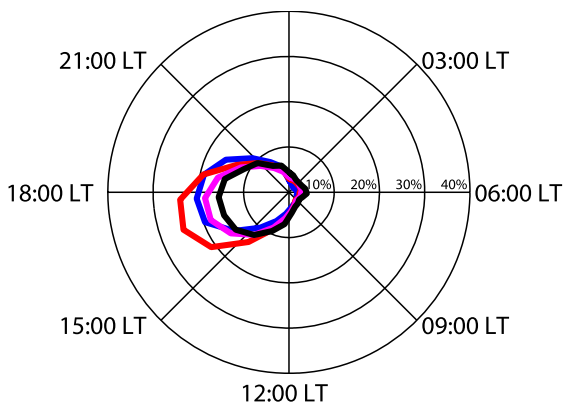

(b) Mar-Apr-May
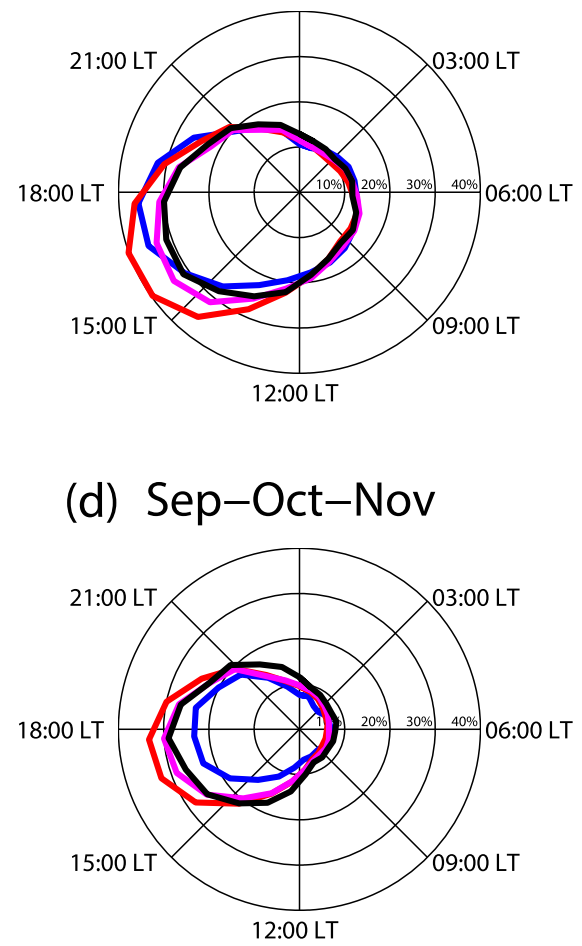

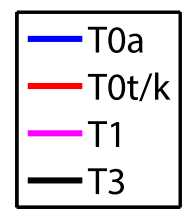

FIG. 10. Diurnal cycle of the mean frequency of IR Tb $<240 \mathrm{~K}$ during each season at the T0a (blue), T0t/k (red), T1 (magenta), and T3 (black) sites (locations are shown in Fig. 1b); LT proceeds clockwise around each circle, and the frequency of IR $\mathrm{Tb}<240 \mathrm{~K}$ is indicated by the distance from the center of the plot.

these correlations are shown in Fig. 12. The correlation of the diurnal cycle between two points largely reflects differences in phase because the correlations are inherently insensitive to differences in the amplitude of the diurnal cycle.

The correlation maps reflect many of the spatially varying effects discussed in sections $3 \mathrm{~b}$ and $3 \mathrm{c}$. Correlations with the T3 site during DJF and MAM are lower in areas where the sea-breeze front is out of phase with the background diurnal cycle. This is apparent to the east of the T3 site and near our eastern sample, where the seabreeze front passes in the middle of the night (Figs. 12a,b). In a similar way, correlations drop off quickly downwind of the $\mathrm{T} 3$ site where the sea-breeze front acts to extend convection even after the sun has set. In terms of the GoAmazon2014/5 sites, during DJF and MAM the T0a site sits near the edge of the region with strong correlations with the diurnal cycle at the T3 site (Figs. 12a,b). Correlations are generally higher across the domain during the dry season (Figs. 12c,d). This is consistent with Figs. $7 \mathrm{c}$ and $7 \mathrm{~d}$, where there are similar albeit smalleramplitude diurnal cycles at the T3 site and each of our four comparison locations distributed across the Amazon basin. Correlations with the $\mathrm{T} 3$ site are lower in regions of elevated terrain during all seasons.

\section{e. Representativeness of the 2014 annual and diurnal cycles}

The final question we set out to answer is to what extent precipitation around the GoAmazon2014/5 sites in 2014 overall and during the two IOPS in particular was representative of the climatological patterns. In other words, were the frequency of deep convection, the mean rain rate, and the phase of the diurnal cycle during the field campaign characteristic of the long-term climatology or was 2014 an outlier year in these respects? To answer this question, we compared the 2014 satellite data with the 2000-13 distributions of precipitation frequency and intensity using both the IR $\mathrm{Tb}<240 \mathrm{~K}$ frequency dataset and the TRMM 3B42 retrievals. Both datasets are available from 2000 to 2014, meaning that we have 14 years of "context" for the 2014 measurements. In Table 2 and Figs. 13 and 14, we show the 2014 annual and diurnal cycles of precipitation in comparison with the 2000-13 distributions. The diurnal cycle comparison focuses on the two IOP periods. For this analysis we averaged the frequency 

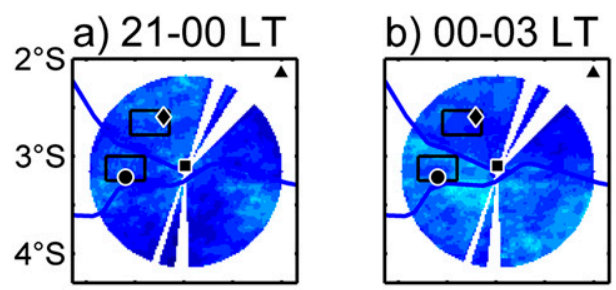

h) $18-21 \mathrm{LT}$
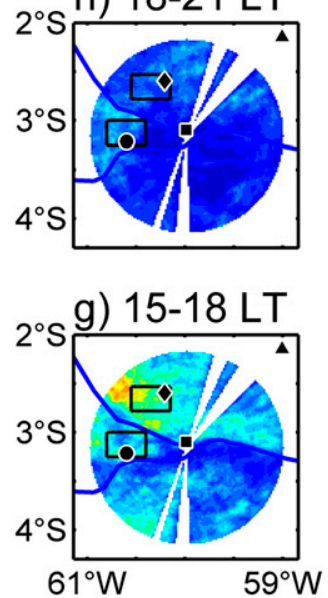
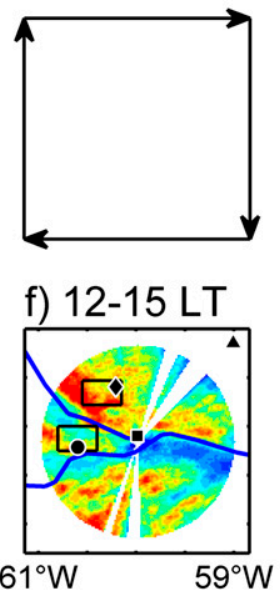

c) 03-06 LT
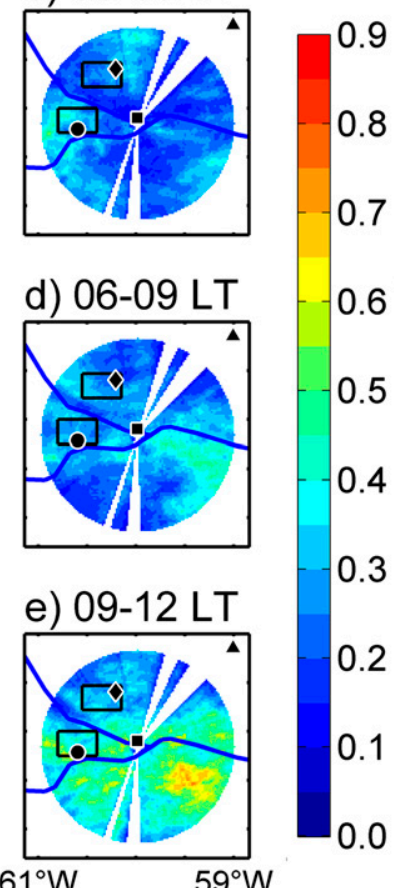

FIG. 11. Mean rain rate from the Brazilian SIPAM S-band radar in 3-h windows across the diurnal cycle during MAM; LT for each 3-h window is indicated at the top of each box. The locations of the GoAmazon2014/5 sites use the same formatting as in Fig. 1a. The averaging boxes around the T3 and T0t/k sites were used to construct Table 1. Areas where the radar beam is blocked by nearby objects are masked out.

and rain-rate estimates within a $2^{\circ}$-diameter box centered on the $\mathrm{T} 3$ site to reduce the noise in the distributions. Our results are not sensitive to this choice of averaging box size (not shown).

In general, the 2014 annual cycle of IR $\mathrm{Tb}<240 \mathrm{~K}$ frequency fell within the 2000-13 climatological distribution (Fig. 13a). The only exception was the month of September, during IOP2, during which the monthly mean frequency of IR $\mathrm{Tb}<240 \mathrm{~K}$ was below the 5 th percentile of the 2000-13 distribution. The TRMM 3B42 precipitation frequency was also below the 5 th percentile during September 2014 (Fig. 13b). The monthly mean TRMM precipitation frequency during March, the second half of IOP1, was above the 75th percentile of the 2000-13 distribution while the monthly mean TRMM 3B42 rain rate was near the 95th percentile (Figs. 13b,c). Closer analysis of the ground-based scanning precipitation radar data made available during the field campaign shows that rain accumulation during March was impacted by six-eight intense storms that tended to pass the T3 site in the early-morning hours (not shown). The annual mean IR Tb $<240 \mathrm{~K}$ frequency was $3.4 \%$ lower in 2014 relative to the mean value from 2000 to 2013 while the annual mean TRMM rain rate was $25.0 \%$ higher (Table 2). In spatial terms, the precipitation anomaly during March 2014 was positive over most of the Amazon basin but is largest over the GoAmazon2014/5 sites (not shown). Martin et al. (2016) discusses the synoptic conditions associated with these anomalies.

TABLE 1. MAM mean frequency of IR Tb colder than $240 \mathrm{~K}$ (IR $\mathrm{Tb}<240 \mathrm{~K}$ ) and mean SIPAM rain rate averaged across the diurnal cycle and from 1200 to $1800 \mathrm{LT}$ at the T3 and T0t/k sites, as well as the relative difference between the two sites. Data were averaged in a $0.25^{\circ}$ latitude $\times 0.40^{\circ}$ longitude box containing each site (Fig. 11). The IR Tb $<240 \mathrm{~K}$ data are averaged over all MAM periods from 2000 to 2014, and the SIPAM data are averaged for MAM 2014-15.

\begin{tabular}{|c|c|c|c|c|c|c|}
\hline & $\begin{array}{c}\text { T3 site: IR } \\
\text { Tb }<240 \mathrm{~K} \\
\text { frequency } \\
\text { for } 2000-14(\%)\end{array}$ & $\begin{array}{c}\text { T0t/k site: IR } \\
\text { Tb }<240 \mathrm{~K} \\
\text { frequency } \\
\text { for } 2000-14(\%)\end{array}$ & $\begin{array}{c}\mathrm{T} 0 \mathrm{t} / \mathrm{k}-\mathrm{T} 3 \\
\text { relative diff }(\%)\end{array}$ & $\begin{array}{c}\text { T3 site: SIPAM } \\
\text { rain rate for } \\
2014-15\left(\mathrm{~mm} \mathrm{day}^{-1}\right)\end{array}$ & $\begin{array}{l}\text { T0t/k site: SIPAM } \\
\text { rain rate for } \\
2014-15\left(\mathrm{~mm} \mathrm{day}^{-1}\right)\end{array}$ & $\begin{array}{l}\mathrm{T} 0 \mathrm{t} / \mathrm{k}-\mathrm{T} 3 \\
\text { relative } \\
\text { diff }(\%)\end{array}$ \\
\hline Diurnal avg & 18.8 & 20.1 & +6.9 & 7.64 & 7.96 & +4.2 \\
\hline $1200-1800$ LT avg & 29.1 & 35.2 & +21.0 & 10.83 & 14.75 & +36.2 \\
\hline
\end{tabular}


(a) Dec-Jan-Feb

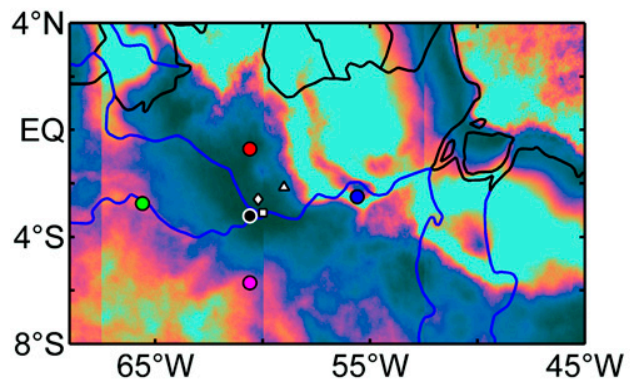

(c)

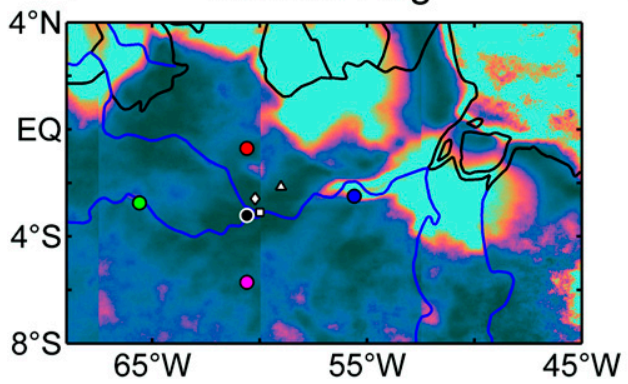

(b)

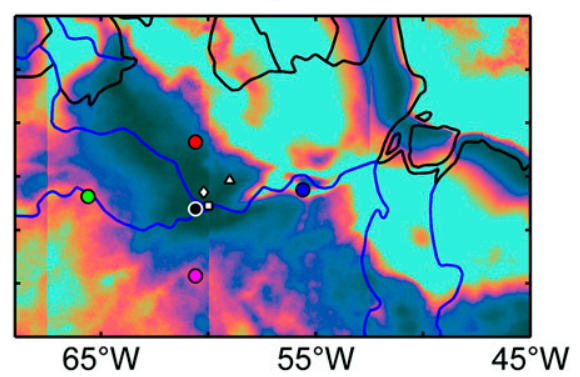

(d)

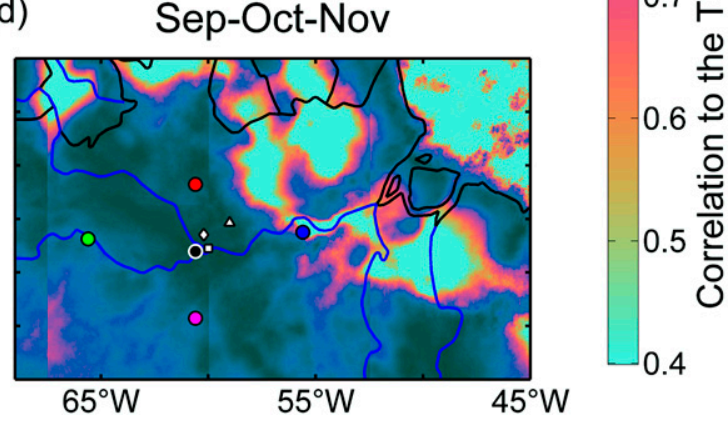

FIG. 12. Correlation at each point with the diurnal cycle of the frequency of IR $\mathrm{Tb}<240 \mathrm{~K}$ at the T3 site during each season. The locations of the GoAmazon2014/5 sites use the same formatting as in Fig. 1a.

One focus area for several investigators analyzing the GoAmazon2014/5 IOP datasets is the diurnal cycle of clouds and precipitation. The diurnal cycle is important because there are common model biases related to the timing and amplitude of the diurnal cycle of clouds and precipitation in both general circulation models and cloudresolving models (e.g., Arakawa and Kitoh 2005; Dai 2006; Wang et al. 2007; Sato et al. 2009). During the IOPs, five radiosonde measurements were made per day so as to better resolve the diurnal variability of the atmosphere. Because of this focus on the diurnal cycle during the IOPs, it makes sense to ask whether the diurnal cycles of IR $\mathrm{Tb}<$ $240 \mathrm{~K}$ frequency observed during the GoAmazon2014/5 IOPs were representative. We show the hourly mean IR $\mathrm{Tb}<240 \mathrm{~K}$ frequency during each IOP in Fig. 14. The limited $(3 \mathrm{~h})$ temporal resolution of the TRMM 3B42 dataset makes the IR $\mathrm{Tb}$ deep-convection proxy more suited to evaluating the representativeness of the IOP diurnal cycles. The diurnal mean IR Tb $<240 \mathrm{~K}$ frequency during the IOP1 period was enhanced by $8.3 \%$ during 2014 relative to the average value from 2000 to 2013, and the diurnal mean frequency during IOP2 was $16.1 \%$ lower than the climatological value (Table 2). The diurnal mean TMRM 3B42 rain rate was $40.0 \%$ larger than the climatological value during IOP1 and $32.1 \%$ larger during IOP2 (Table 2). The diurnal cycles of the IR Tb $<240 \mathrm{~K}$ frequency during both IOPs were broadly representative of the 2000-13 distributions for the same periods.
Deep-convection frequency around the GoAmazon2014/5 sites begins to increase after $0900 \mathrm{LT}$ and reaches a diurnal maximum between 1500 and 1800 LT. After 2100 LT the frequency of deep convection holds at a fairly steady nocturnal value during both IOP periods. The diurnal peak of convection during the IOP1 period is broader and occurs earlier in the day than during the IOP2 period. This may result from the passage of the sea-breeze front at the T3 site during the wet season. The IR $\mathrm{Tb}<240 \mathrm{~K}$ frequency from 0000 to $1300 \mathrm{LT}$ during IOP1 tended to be close to the 75 th percentile of the 2000-13 distribution, indicating slightly more frequent deep convection than normal. During IOP2, convection from 1600 to $0300 \mathrm{LT}$ tended to be more suppressed when compared with the 2000-13 distribution. The variability of the $2000-13$ IR Tb $<240 \mathrm{~K}$ frequency distributions was generally larger during the IOP1 period than during the IOP2 time frame.

\section{Conclusions}

We set out to provide spatial and temporal context for the point measurements of clouds and precipitation at the ground sites distributed around Manaus during the GoAmazon2014/5 field campaign. The observations collected during GoAmazon2014/5 constitute one of the most comprehensive datasets over the Amazon, but they are inherently limited in space and time and are thus 


\section{Monthly Mean IR Tb < 240 K Frequency}

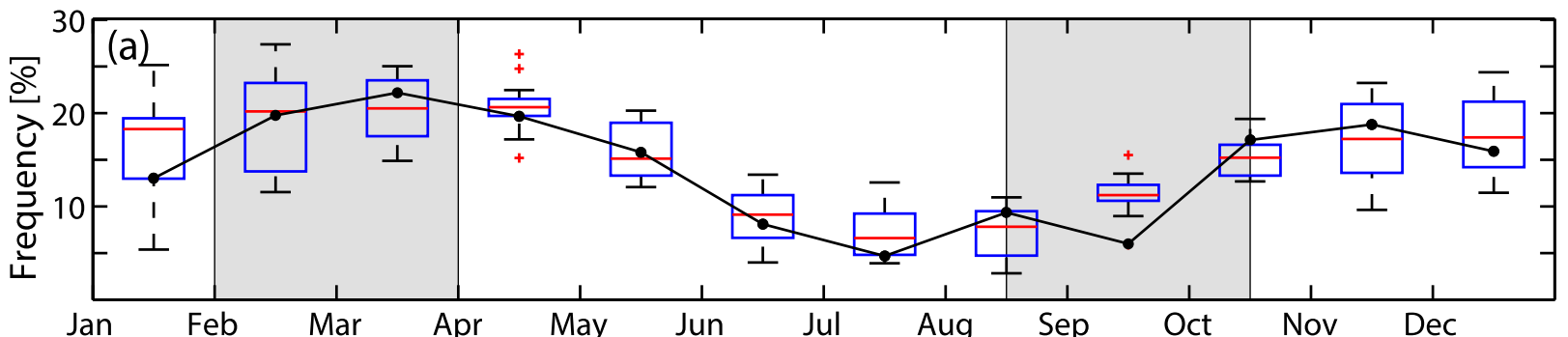

Monthly Mean TRMM 3B42 Precipitation Frequency

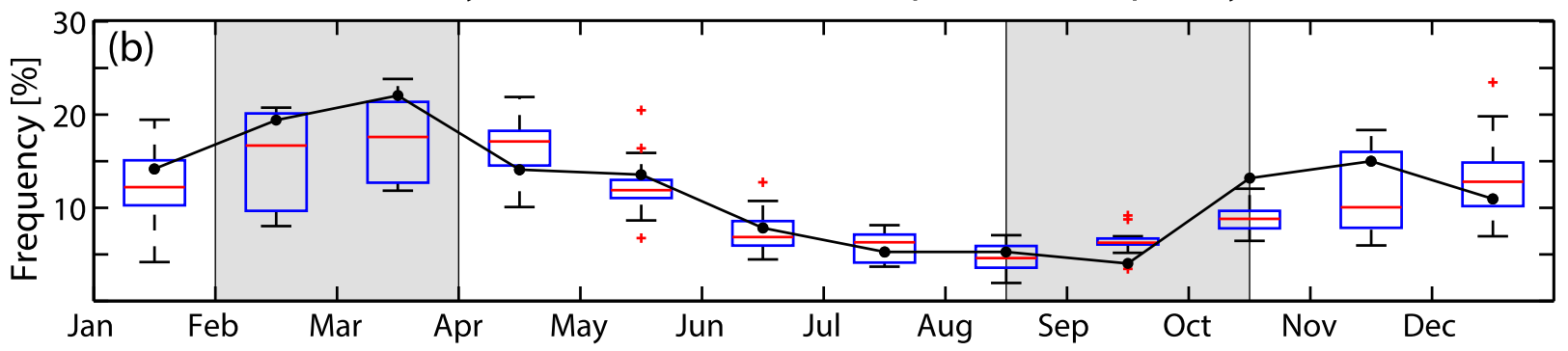

Monthly Mean TRMM 3B42 Rainrate

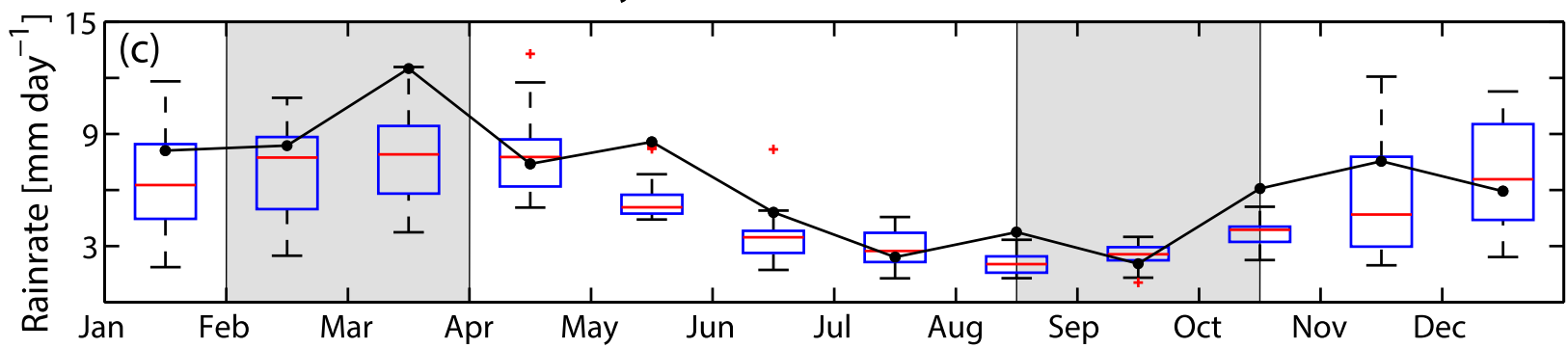

FIG. 13. Distributions of the monthly mean (a) frequency of IR Tb $<240 \mathrm{~K}$, (b) TRMM 3B42 precipitation frequency, and (c) TRMM $3 \mathrm{~B} 42$ rain rate. All values are averaged in a $2^{\circ}$ box centered on the T3 site. The box plots show the distributions of values from 2000 to 2013 , and the black dots and lines show the 2014 values. In the box plots, the red lines indicate the mean value, the blue boxes indicate the area between the 25 th and 75 th percentiles, the black whiskers indicate the area between the 5th and 95th percentiles, and the red crosses indicate years beyond the 5 th or 95 th percentiles. The shaded areas indicate the periods of IOP1 and IOP2.

subject to representativeness issues. These issues are reflected in the spatial noise of the seasonal mean rain-rate measurements from the Manaus SIPAM radar during the campaign (Fig. 11) and can be illustrated by comparing the size of the SIPAM radar domain with the vastness of the Amazon basin (Fig. 1a). The baseline context of natural conditions that emerges from our analysis could eventually form the basis for future studies examining the anthropogenic impact of Manaus on aerosols, clouds, and precipitation. Our science questions were threefold: 1) How do the river-driven circulations around Manaus and the inland propagation of the sea-breeze front affect the diurnal cycle of deep convection around the GoAmazon2014/5 sites? 2) Are the characteristics of the diurnal cycle of deep convection around the GoAmazon2014/5 sites similar to other locations in the Amazon basin? 3) Was 2014, the principal year of the field campaign and the year of the two IOPs, a representative year for studying deep convection in the Amazon? Answering each of these questions serves as a critical first step toward interpreting and generalizing the findings from the time-limited point measurements made during the field campaign.

We use the frequency of cold cloud tops (IR Tb $<$ $240 \mathrm{~K}$ ) as a proxy for deep convection and use the diurnal cycle as a lens through which to view the similarities and differences between the sites. Here we list the three primary results of our analysis:

1) In agreement with previous work, convection associated with the inland propagation of the seabreeze front during the wet season happens to be in phase with the background diurnal cycle of deep convection around the GoAmazon2014/5 sites but 
Hourly Mean IR Tb $<240$ K Frequency in IOP1
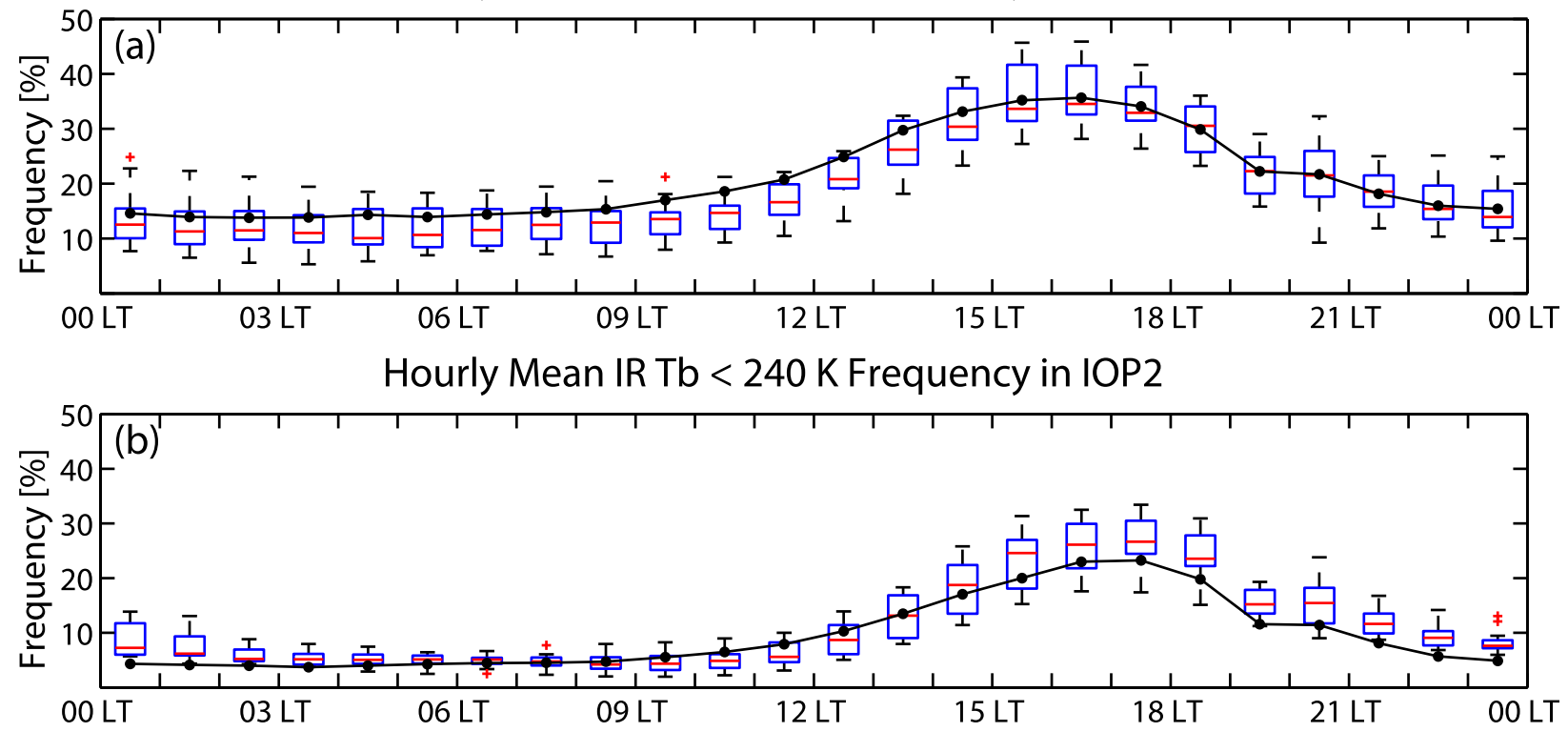

FIG. 14. Distributions of the hourly mean frequency of IR Tb $<240 \mathrm{~K}$ during (a) IOP1 (1 Feb-31 Mar 2014) and (b) IOP2 (15 Aug-15 Oct 2014). All values are averaged in a $2^{\circ}$ box centered on the T3 site, and time is expressed as LT at the T3 site. The box plots show the distributions of values from 2000 to 2013, and the black dots and lines show the 2014 values. In the box plots, the red lines indicate the mean value, the blue lines indicate the area between the 25 th and 75 th percentiles, the black whiskers indicate the area between the 5 th and 95 th percentiles, and the red crosses indicate years beyond the 5 th or 95 th percentiles.

is out of phase a few hundred kilometers to the east and west of the field campaign sites (Garstang et al. 1994; Cutrim et al. 2000; Angelis et al. 2004). This creates a diurnal cycle of IR Tb $<240 \mathrm{~K}$ frequency at the GoAmazon2014/5 sites that has only a single afternoon peak. In contrast, a bimodal diurnal cycle of convection is observed at a hypothetical comparison site located along the Amazon River but $5^{\circ}$ east of the $\mathrm{T} 3$ site.

2) The smaller north-south-oriented tributaries flowing into the Amazon River have patterns of enhanced IR $\mathrm{Tb}<240 \mathrm{~K}$ frequency on their eastern shores and a weak suppression over the river and on the downwind side (Silva Dias et al. 2004; Lu et al. 2005; dos Santos et al.2014). This pattern results in up to a $21 \%$ more frequent occurrence of afternoon deep convection and a $36 \%$ higher afternoon rain rate at the $\mathrm{T} 0 \mathrm{t} / \mathrm{k}$ sites relative to the T3 site. Any interpretation of variability between the GoAmazon2014/5 sites upwind and downwind of Manaus must take into account the location of the sites with respect to the Negro and Amazon Rivers.

3) The annual cycles of IR Tb $<240 \mathrm{~K}$ frequency and TRMM 3B42 rain rate during 2014 were broadly representative of the $2000-13$ distributions. The diurnal mean IR $\mathrm{Tb}<240 \mathrm{~K}$ frequency during the IOP1 period was $8.3 \%$ higher than the mean value from 2000 to 2013 and was $16.1 \%$ lower during IOP2. The diurnal mean TRMM 3B42 rain rate during IOP1 was $40.0 \%$ higher than the mean value from 2000 to 2013 and $32.1 \%$ higher during IOP2.

These findings build on previous work showing that the frequency of deep convection in the Amazon basin is spatially heterogeneous, with a number of physical processes jointly determining the timing and frequency

TABLE 2. Mean frequency of IR Tb $<240 \mathrm{~K}$ and mean TRMM 3B42 rain rate during all of 2014, the GoAmazon2014/5 IOP1 period (1 Feb-31 Mar 2014), and the GoAmazon2014/5 IOP2 period (15 Aug-15 Oct 2014) in comparison with the mean values in the same windows from 2000 to 2013. All values are averaged in a $2^{\circ}$-diameter box centered on the T3 site.

\begin{tabular}{|c|c|c|c|c|c|c|}
\hline & $\begin{array}{c}\text { IR } \mathrm{Tb}<240 \mathrm{~K} \\
\text { frequency } \\
2000-13(\%)\end{array}$ & $\begin{array}{c}\text { IR } \mathrm{Tb}<240 \mathrm{~K} \\
\text { frequency } \\
2014(\%)\end{array}$ & $\begin{array}{l}\text { Relative } \\
\text { diff (\%) }\end{array}$ & $\begin{array}{l}\text { TRMM rain } \\
\text { rate } 2000-13 \\
\left(\mathrm{~mm} \mathrm{day}^{-1}\right)\end{array}$ & $\begin{array}{l}\text { TRMM rain rate } \\
2014\left(\mathrm{~mm} \mathrm{day}^{-1}\right)\end{array}$ & Relative diff (\%) \\
\hline Annual mean & 14.7 & 14.2 & -3.4 & 5.2 & 6.5 & +25.0 \\
\hline IOP1 mean & 19.3 & 20.9 & +8.3 & 7.5 & 10.5 & +40.0 \\
\hline IOP2 mean & 11.2 & 9.4 & -16.1 & 2.8 & 3.7 & +32.1 \\
\hline
\end{tabular}


of deep convection (e.g., Kousky 1980; Garstang et al. 1990, 1994; Greco et al. 1990; Cohen et al. 1995, 2014; Cutrim et al. 2000; Negri et al. 2000; Angelis et al. 2004; Silva Dias et al. 2004; Janowiak et al. 2005; Lu et al. 2005; Fitzjarrald et al. 2008). Our analysis illustrates how these spatially varying effects may be aliased onto the diurnal cycles observed at the field campaign sites. If the GoAmazon2014/5 sites had been located a few hundred kilometers to the east or west of their chosen location, or if they were positioned differently with respect to the rivers in the Manaus confluence region, then the diurnal cycle they observed would have likely had a different phase and amplitude. Within the context of the GoAmazon2014/5 science questions, this also indicates that data from the T3 site located downwind of Manaus should be used carefully in comparisons with the measurements made at the T0a, T0e, T0t/k, T1, and T2 sites, which were located to the east of the Negro River and, in the case of the T0a site, significantly farther away from the Amazon River. From a climatological standpoint, the T0e, T0t/k, and $\mathrm{T} 1$ sites experience up to $10 \%$ more frequent afternoon deep convection relative to the $\mathrm{T} 3$ site as a result of their position along the eastern shores of the Negro River as opposed to the western shore.

The results presented in this paper could also be useful to those using the GoAmazon2014/5 observations to evaluate simulations of the diurnal cycle of deep convection in the Amazon basin. Because the river circulation patterns affect the diurnal cycle of convection frequency and, in particular, because of the fact that the GoAmazon2014/5 sites are within an area influenced by the Amazon, Negro, and Solimões Rivers, the impact of the rivers on the GoAmazon2014/5 observations should be accounted for when using the field-campaign data to evaluate model performance at other locations away from the rivers. Furthermore, coarse-resolution simulations may struggle to represent the details of the river circulations, which are clearly important for determining the patterns of precipitation observed at the GoAmazon2014/5 sites.

Acknowledgments. This research is based on work supported by the U.S. Department of Energy (DOE) Office of Science, Biological and Environmental Research as part of the Atmospheric System Research (ASR) program. We acknowledge the logistical support during GoAmazon2014/5 from the ARM Climate Research Facility, a DOE Office of Science user facility sponsored by the Office of Biological and Environmental Research. The work was conducted under 001030/2012-4 of the Brazilian National Council for Scientific and Technological Development (CNPq). The Pacific Northwest National Laboratory is operated for
DOE by Battelle Memorial Institute under Contract DE-AC06-76RLO 1830. We thank Aaron Funk and Courtney Schumacher for providing the gridded SIPAM radar data. Special thanks are given to Larry Berg, Jennifer Comstock, Laura Riihimaki, and Hailong Wang for their suggestions on improving this work. David Fitzjarrald and two anonymous reviewers provided valuable feedback.

\section{REFERENCES}

Adams, D. K., and Coauthors, 2011: A dense GNSS meteorological network for observing deep convection in the Amazon. Atmos. Sci. Lett., 12, 207-212, doi:10.1002/asl.312.

Anagnostou, E. N., A. J. Negri, and R. F. Adler, 1999: A satellite infrared technique for diurnal rainfall variability studies. J. Geophys. Res., 104, 31 477-31 488, doi:10.1029/ 1999JD900157.

Angelis, C. F., G. R. McGregor, and C. Kidd, 2004: Diurnal cycle of rainfall over the Brazilian Amazon. Climate Res., 26, 139-149, doi:10.3354/cr026139.

Arakawa, O., and A. Kitoh, 2005: Rainfall diurnal variation over the Indonesian Maritime Continent simulated by $20 \mathrm{~km}-\mathrm{mesh}$ GCM. SOLA, 1, 109-112, doi:10.2151/sola.2005-029.

Betts, A. K., J. D. Fuentes, M. Garstang, and J. H. Ball, 2002: Surface diurnal cycle and boundary layer structure over Rondônia during the rainy season. J. Geophys. Res., 107, 8065 , doi:10.1029/2001JD000356.

Biasutti, M., and S. E. Yuter, 2013: Observed frequency and intensity of tropical precipitation from instantaneous estimates. J. Geophys. Res. Atmos., 118, 9534-9551, doi:10.1002/ jgrd.50694.

,-- C C. D. Burleyson, and A. H. Sobel, 2012: Very high resolution rainfall patterns measured by TRMM Precipitation Radar: Seasonal and diurnal cycles. Climate Dyn., 39, 239-258, doi:10.1007/s00382-011-1146-6.

Cohen, J. C. P., M. A. F. Silva Dias, and C. A. Nobre, 1995: Environmental conditions associated with Amazonian squall lines: A case study. Mon. Wea. Rev., 123, 3163-3174, doi:10.1175/ 1520-0493(1995)123<3163:ECAWAS>2.0.CO;2.

_ D. R. Fitzjarrald, F. A. F. D’Oliveira, I. Saraiva, I. R. da Silva Barbosa, A. W. Gandu, and P. A. Kuhn, 2014: Radar-observed spatial and temporal rainfall variability near the TapajósAmazon confluence. Rev. Bras. Meteor., 29, 23-30, doi:10.1590/0102-778620130058.

Cutrim, E. M. C., D. W. Martin, D. G. Butzow, I. M. Silva, and E. Yulaeva, 2000: Pilot analysis of hourly rainfall in central and eastern Amazonia. J. Climate, 13, 1326-1334, doi:10.1175/ 1520-0442(2000)013<1326:PAOHRI > 2.0.CO;2.

Dai, A., 2001: Global precipitation and thunderstorm frequencies. Part I: Seasonal and interannual variations. J. Climate, 14, 1092-1111, doi:10.1175/1520-0442(2001)014<1092: GPATFP $>2.0 . \mathrm{CO} ; 2$.

- 2006: Precipitation characteristics in eighteen coupled climate models. J. Climate, 19, 4605-4630, doi:10.1175/ JCLI3884.1.

de Oliveira, A. P., and D. R. Fitzjarrald, 1993: The Amazon River breeze and the local boundary layer: I. Observations. Bound.Layer Meteor., 63, 141-162, doi:10.1007/BF00705380.

dos Santos, M. J., M. A. F. Silva Dias, and E. D. Freitas, 2014: Influence of local circulations on wind, moisture, and precipitation 
close to Manaus City, Amazon Region, Brazil. J. Geophys. Res., 119, 13 233-13 249, doi:10.1002/2014JD021969.

Feng, Z., X. Dong, B. Xi, C. Schumacher, P. Minnis, and M. Khaiyer, 2011: Top-of-atmosphere radiation budget of convective core/ stratiform rain and anvil clouds from deep convective systems. J. Geophys. Res., 116, D23202, doi:10.1029/2011JD016140.

Ferreira, R. N., T. M. Rickenback, D. L. Herdies, and L. M. V. Carvalho, 2003: Variability of South American convective cloud systems and tropospheric circulation during JanuaryMarch 1998 and 1999. Mon. Wea. Rev., 131, 961-973, doi:10.1175/1520-0493(2003)131<0961:VOSACC > 2.0.CO;2.

Fitzjarrald, D. R., R. K. Sakai, O. L. L. Moraes, R. C. de Oliveira, O. C. Acevedo, M. J. Czikowsky, and T. Beldini, 2008: Spatial and temporal rainfall variability near the Amazon-Tapajós confluence. J. Geophys. Res., 113, G00B11, doi:10.1029/ 2007JG000596.

Gan, M. A., V. E. Kousky, and C. F. Ropelewski, 2004: The South American monsoon circulation and its relationship to rainfall over west-central Brazil. J. Climate, 17, 47-66, doi:10.1175/ 1520-0442(2004)017<0047:TSAMCA >2.0.CO;2.

Garstang, M., and Coauthors, 1990: The Amazon BoundaryLayer Experiment (ABLE 2B): A meteorological perspective. Bull. Amer. Meteor. Soc., 71, 19-32, doi:10.1175/ 1520-0477(1990)071<0019:TABLEA>2.0.CO;2.

_- , H. L. Massie Jr., J. Halverson, S. Greco, and J. Scala, 1994: Amazon coastal squall lines. Part I: Structure and kinematics. Mon. Wea. Rev., 122, 608-622, doi:10.1175/ 1520-0493(1994)122<0608:ACSLPI > 2.0.CO;2.

Greco, S., and Coauthors, 1990: Rainfall and surface kinematic conditions over central Amazonia during ABLE-2B. J. Geophys. Res., 95, 17 001-17 014, doi:10.1029/JD095iD10p17001.

Gulizia, C., and I. Camilloni, 2015: Comparative analysis of the ability of a set of CMIP3 and CMIP5 global climate models to represent precipitation in South America. Int. J. Climatol., 35 , 583-595, doi:10.1002/joc.4005.

Harriss, R. C., and Coauthors, 1990: The Amazon Boundary Layer Experiment: Wet season 1987. J. Geophys. Res., 95, 1672116736, doi:10.1029/JD095iD10p16721.

Hohenegger, C., and B. Stevens, 2013: Preconditioning deep convection with cumulus congestus. J. Atmos. Sci., 70, 448-464, doi:10.1175/JAS-D-12-089.1.

Huffman, G. J., and Coauthors, 2007: The TRMM Multisatellite Precipitation Analysis: Quasi-global, multiyear, combinedsensor precipitation estimates at fine scale. J. Hydrometeor., 8, 38-55, doi:10.1175/JHM560.1.

IBGE, 2015: Amazonas: Manaus. Instituto Brasileiro de Geografia e Estatstica, accessed 30 November 2015. [Available online at http://cidades.ibge.gov.br/xtras/perfil.php?codmun=130260.]

Janowiak, J. E., R. J. Joyce, and Y. Yarosh, 2001: A real-time global half-hourly pixel-resolution infrared dataset and its applications. Bull. Amer. Meteor. Soc., 82, 205-217, doi:10.1175/1520-0477(2001)082<0205:ARTGHH>2.3.CO;2.

_ , V. E. Kousky, and R. J. Joyce, 2005: Diurnal cycle of precipitation determined from the CMORPH high spatial and temporal resolution global precipitation analyses. J. Geophys. Res., 110, D23105, doi:10.1029/2005JD006156.

Joetzjer, E., H. Douville, C. Delire, and P. Ciais, 2013: Present-day and future Amazonian precipitation in global climate models: CMIP5 versus CMIP3. Climate Dyn., 41, 2921-2936, doi:10.1007/s00382-012-1644-1.

Jones, C., and L. M. V. Carvalho, 2013: Climate change in the South American monsoon system: Present climate and
CMIP5 projections. J. Climate, 26, 6660-6678, doi:10.1175/ JCLI-D-12-00412.1.

Joyce, R. J., J. E. Janowiak, P. A. Arkin, and P. Xie, 2004: CMORPH: A method that produces global precipitation estimates from passive microwave and infrared data at high spatial and temporal resolution. J. Hydrometeor., 5, 487-503, doi:10.1175/1525-7541(2004)005<0487:CAMTPG>2.0.CO;2.

Kousky, V. E., 1980: Diurnal rainfall variations in northeast Brazil. Mon. Wea. Rev., 108, 488-498, doi:10.1175/ 1520-0493(1980)108<0488:DRVINB > 2.0.CO;2.

Laurent, H., L. A. T. Machado, C. A. Morales, and L. Durieux, 2002: Characteristics of the Amazonian mesoscale convective systems observed from satellite and radar during the WETAMC/LBA experiment. J. Geophys. Res., 107, 8054, doi:10.1029/2001JD000337.

Lu, L., A. S. Denning, M. A. da Silva-Dias, P. da Silva-Dias, M. Longo, S. R. Freitas, and S. Saatchi, 2005: Mesoscale circulations and atmospheric $\mathrm{CO}_{2}$ variations in the Tapajós region, Pará, Brazil. J. Geophys. Res., 110, D21102, doi:10.1029/ 2004JD005757.

Machado, L. A. T., W. B. Rossow, R. L. Guedes, and A. W. Walker, 1998: Life cycle variations of mesoscale convective systems over the Americas. Mon. Wea. Rev., 126, 1630-1654, doi:10.1175/1520-0493(1998)126<1630: LCVOMC $>2.0 . \mathrm{CO} ; 2$.

— , and Coauthors, 2014: The CHUVA Project: How does convection vary across Brazil? Bull. Amer. Meteor. Soc., 95, 1365-1380, doi:10.1175/BAMS-D-13-00084.1.

Martin, C. L., D. Fitzjarrald, M. Garstang, A. P. Oliveira, S. Greco, and E. Browell, 1988: Structure and growth of the mixing layer over the Amazonian rain forest. J. Geophys. Res., 93, 1361-1375, doi:10.1029/JD093iD02p01361.

Martin, S. T., and Coauthors, 2016: Introduction: Observations and Modeling of the Green Ocean Amazon (GoAmazon2014/5). Atmos. Chem. Phys., 16, 4785-4797, doi:10.5194/ acpd-15-30175-2015.

Mather, J. H., and J. W. Voyles, 2013: The ARM Climate Research Facility: A review of structure and capabilities. Bull. Amer. Meteor. Soc., 94, 377-392, doi:10.1175/BAMS-D-11-00218.1.

Negri, A. J., E. N. Anagnostou, and R. F. Adler, 2000: A 10-yr climatology of Amazonian rainfall derived from passive microwave satellite observations. J. Appl. Meteor., 39, 42-56, doi:10.1175/1520-0450(2000)039<0042:AYCOAR>2.0.CO;2.

, L. Xu, and R. F. Adler, 2002: A TRMM-calibrated infrared rainfall algorithm applied over Brazil. J. Geophys. Res., 107, 8048, doi:10.1029/2000JD000265.

Paiva, R. C. D., D. C. Buarque, R. T. Clarke, W. Collischonn, and D. G. Allasia, 2011: Reduced precipitation over large water bodies in the Brazilian Amazon shown from TRMM data. Geophys. Res. Lett., 38, L04406, doi:10.1029/ 2010GL045277.

Raia, A., and I. F. A. Cavalcanti, 2008: The life cycle of the South American monsoon system. J. Climate, 21, 6227-6246, doi:10.1175/ 2008JCLI2249.1.

Rao, V. B., I. F. A. Cavalcanti, and K. Hada, 1996: Annual variation of rainfall over Brazil and water vapor characteristics over South America. J. Geophys. Res., 101, 26539-26551, doi:10.1029/96JD01936.

Rickenbach, T. M., 2004: Nocturnal cloud systems and the diurnal variation of clouds and rainfall in southwestern Amazonia. Mon. Wea. Rev., 132, 1201-1219, doi:10.1175/ 1520-0493(2004)132<1201:NCSATD>2.0.CO;2. 
Sato, T., H. Miura, M. Satoh, Y. N. Takayabu, and Y. Wang, 2009: Diurnal cycle of precipitation in the tropics simulated in a global cloud-resolving model. J. Climate, 22, 4809-4826, doi:10.1175/2009JCLI2890.1.

Schumacher, C., and R. A. Houze Jr., 2006: Stratiform precipitation production over sub-Saharan Africa and the tropical East Atlantic as observed by TRMM. Quart. J. Roy. Meteor. Soc., 132, 2235-2255, doi:10.1256/qj.05.121.

Silva Dias, M. A. F., P. L. Silva Dias, M. Longo, D. R. Fitzjarrald, and A. S. Denning, 2004: River breeze circulation in eastern Amazonia: Observations and modelling results. Theor. Appl. Climatol., 78, 111-121, doi:10.1007/ s00704-004-0047-6.

Tanaka, L. M. S., P. Satyamurty, and L. A. T. Machado, 2014: Diurnal variation of precipitation in central Amazon Basin. Int. J. Climatol., 34, 3574-3584, doi:10.1002/joc.3929.

Trenberth, K. E., and D. P. Stepaniak, 2004: The flow of energy through the earth's climate system. Quart. J. Roy. Meteor. Soc., 130, 2677-2701, doi:10.1256/qj.04.83.
Wang, Y., L. Zhou, and K. Hamilton, 2007: Effect of convective entrainment/detrainment on simulation of tropical precipitation diurnal cycle. Mon. Wea. Rev., 135, 567-585, doi:10.1175/MWR3308.1.

Yin, L., R. Fu, E. Shevliakova, and R. E. Dickinson, 2013: How well can CMIP5 simulate precipitation and its controlling processes over tropical South America? Climate Dyn., 41, 3127-3143, doi:10.1007/s00382-012-1582-y.

Zeng, Z., S. Piao, X. Lin, G. Yin, S. Peng, P. Ciais, and R. B. Myneni, 2012: Global evapotranspiration over the past three decades: Estimation based on the water balance equation combined with empirical models. Environ. Res. Lett., 7, 014026, doi:10.1088/1748-9326/7/1/014026.

Zhou, J., and K.-M. Lau, 1998: Does a monsoon climate exist over South America? J. Climate, 11, 1020-1040, doi:10.1175/ 1520-0442(1998)011<1020:DAMCEO > 2.0.CO;2.

Zipser, E. J., C. Liu, D. J. Cecil, S. W. Nesbitt, and D. P. Yorty, 2006: Where are the most intense thunderstorms on Earth? Bull. Amer. Meteor. Soc., 87, 1057-1071, doi:10.1175/ BAMS-87-8-1057. 